Repository of the Max Delbrück Center for Molecular Medicine (MDC) Berlin (Germany)

http://edoc.molc-berlin.de/14371/

\title{
A somatosensory circuit for cooling perception in mice.
}

Milenkovic, N., Zhao, W.J., Walcher, J., Albert, T., Siemens, J., Lewin, G.R., Poulet, J.F.A. 


\section{A somatosensory circuit for cooling perception in mice}

Nevena Milenkovic ${ }^{1,2}$, Wen-Jie Zhao ${ }^{1,2,4}$, Jan Walcher ${ }^{1,2,4}$, Tobias Albert ${ }^{1,2,4}$, Jan Siemens ${ }^{3}$, Gary R. Lewin ${ }^{1,2}$ and James F.A. Poulet ${ }^{1,2 *}$

${ }^{1}$ Department of Neuroscience, Max-Delbrück Center for Molecular Medicine (MDC), Berlin-Buch, Germany.

${ }^{2}$ Neuroscience Research Center and Cluster of Excellence NeuroCure, Charité-Universitätsmedizin Berlin, Berlin, Germany.

${ }^{3}$ Department of Pharmacology, Heidelberg University, Heidelberg, Germany

${ }^{4}$ These authors made equal contributions to this work

${ }^{*}$ Correspondence to be addressed to:

James Poulet,

Max Delbrück Center for Molecular Medicine (MDC),

Robert-Rössle-Str. 10,

10392 Berlin-Buch,

Germany.

Telephone: ++49 (0) 30450639795

Fax: ++49 (0) 30450539979

E-Mail: james.poulet@mdc-berlin.de

Website: http://www.mdc-berlin.de/poulet 


\section{ABSTRACT}

The temperature of an object provides important somatosensory information for animals performing tactile tasks. Humans can perceive skin cooling of less than one degree, but the sensory afferents and central circuits they engage to enable the perception of surface temperature are poorly understood. To address these questions, we examined the perception of glabrous skin cooling in mice. We found that mice were also capable of perceiving small amplitude skin cooling and that primary somatosensory (S1) cortical neurons were required for cooling perception. Moreover, the absence of the menthol-gated transient receptor potential melastatin 8 ion channel in sensory afferent fibers eliminated the ability to perceive cold and the corresponding activation of S1 neurons. Our results identify parts of a neural circuit underlying cold perception in mice and provide a new model system for the analysis of thermal processing and perception and multimodal integration.

An accurate sense of surface temperature helps animals to perceive object structure and identity. Psychophysical experiments have shown that humans are able to perceive tiny changes in skin cooling with a range between 0.4 and $1.8{ }^{\circ} \mathrm{C}^{1,2}$. It has, however, proved challenging to assess the perceptual ability of rodents to discriminate small temperature steps at threshold levels. Classical paw withdrawal tests cannot differentiate between reflexive avoidance behavior and sensory perception ${ }^{3}$. Two-plate thermal preference arenas have shown that mice avoid cooler floor temperatures ${ }^{4-6}$, but this test has limited spatial and temporal control of the stimulus and lacks fine-grained resolution for near threshold perception. We therefore developed a shortlatency, goal-directed thermal perception task using the glabrous skin of the mouse forepaw.

A general dogma is that all somatosensory input, including thermal, is integrated by the primary somatosensory cortex (S1) to form a coherent sensory percept. S1 is necessary for tactile somatosensory perception in rodents $^{7-13}$. The role of S1 in thermal perception, however, is under debate, 
with three studies concluding that rodent $\mathrm{S} 1$ is not involved ${ }^{14-16}$ and another concluding that it is ${ }^{17}$. This may be because these studies used large cortical lesions with long recovery and retraining periods in freely moving rats that used facial regions to detect temperature ${ }^{14-17}$.

Likewise, very little is known about the underlying cortical neural processing of non-noxious thermal stimuli in rodents. To the best of our knowledge, only one study, conducted in anesthetized rats stimulating scrotal skin, has shown extracellular responses of cortical neurons to thermal stimulation ${ }^{18}$. At the sensory periphery, a range of primary afferents including myelinated $A \beta$ mechanoreceptors ${ }^{2,19}$, thinly myelinated A $\delta$-fibers and unmyelinated polymodal $C$ fibers, fire during skin cooling ${ }^{4,20,21}$. Although it is thought that thickly myelinated $A \delta$ fibers are responsible for cooling perception, C fibers have been recorded with low thresholds for cooling ${ }^{4,21-23}$ and could also contribute to the perception of mild cold.

To identify the neural pathways and brain regions involved in cooling perception, we studied the forepaw somatosensory system of mice. We found that mice could perceive glabrous skin cooling and that forepaw S1 processes both thermal and tactile input and is required for mild cold thermal perception. Finally, we found that expression of the menthol-activated transient receptor potential melastatin 8 (TRPM8) ion channel in glabrous skin afferent neurons is required for the detection of perceptually relevant mild cooling temperature information. 


\section{RESULTS}

\section{A temperature perception task for head-restrained mice}

To investigate the perceptual ability of mice to detect mild skin cooling, we developed a thermal perception task in head-restrained, arm-tethered mice. Mice quickly adapt to arm-tethering, allowing us to present thermal stimuli using a Peltier element positioned against the glabrous skin of digits 2, 3 and 4 of the right forepaw (Fig. 1a). The thermal stimulator was held at $32{ }^{\circ} \mathrm{C}$ throughout the experiment and then rapidly reduced in temperature by $10^{\circ} \mathrm{C}$ in $0.5 \mathrm{~s}$, held at $22{ }^{\circ} \mathrm{C}$ for $2 \mathrm{~s}$ and returned to $32^{\circ} \mathrm{C}$ in $0.5 \mathrm{~s}\left(32-22{ }^{\circ} \mathrm{C}\right.$, total duration of $3 \mathrm{~s}$ ) at random time intervals. Mice were rewarded with water droplets for licking within a 3-s window of opportunity following the thermal stimulus onset (Fig. 1b and Supplementary Fig. 1). A time-out was imposed if mice licked within the 2-s period before the stimulus. Stimulus trials were mixed with catch trials, where no stimulus was presented, at 50:50. Mice learnt to report a $32-22{ }^{\circ} \mathrm{C}$ thermal stimulus in the first training session and then gradually improved their hit rate during subsequent training sessions (Fig. 1c and Supplementary Fig. 1). We then reduced the amplitude of the cold stimuli in separate training sessions to assess the threshold for cooling perception. Mice were able to report a temperature reduction of $2{ }^{\circ} \mathrm{C}$ from skin temperature with high success rates (Fig. 1d), placing mouse cooling detection performance in a similar range as that of healthy humans ${ }^{1,2}$.

\section{Cortical processing of mild cooling and tactile stimuli}

To assess whether mouse forepaw S1 is involved in processing of nonnoxious cooling stimulation of the paw, we first performed intrinsic optical imaging during cooling and tactile stimulation in isoflurane anesthetized mice (Fig. 2a,b). In all mice $(n=8)$, cooling and tactile stimulation of the paw generated an overlapping intrinsic optical signal over forepaw S1 with $78.9 \pm$ $6.4 \%$ of the area evoked by cooling overlapping the touch response (Fig. 2c,d) and the distance between the peaks of the intrinsic signal being $187.8 \pm$ $27.4 \mu \mathrm{m}$. These data suggest that there are neurons located in forepaw S1 that respond to cooling thermal and/or to touch stimuli. 
To directly assess neuronal activity in S1, we next made whole-cell patchclamp recordings from forepaw S1 cortical layer 2/3 (L2/3) neurons during cooling and tactile stimulation of the forepaw in awake head-restrained mice (Fig. 3a-c). $32-22{ }^{\circ} \mathrm{C}$ stimuli were presented to digits $2-4$ at 0.1 or $0.05 \mathrm{~Hz}$, with a subset of mice also stimulated with a $100-\mathrm{Hz}, 300-\mathrm{ms}$ vibrotactile stimulus. Cooling of the forepaw digits triggered a subthreshold response in 13 of 17 neurons (range $=-3.6 \mathrm{mV}-13.2 \mathrm{mV}$; Fig. 3d) and tactile stimulation triggered a subthreshold response in seven of ten neurons (range $=-4.0-13.9$ $\mathrm{mV}$; Fig. 3d). A comparison of the absolute evoked membrane potential response amplitude showed no significant difference between cooling and tactile stimuli (cooling, $n=17$ neurons, $5.12 \pm 0.7 \mathrm{mV}$; tactile, $n=10$ neurons, $7.4 \pm 1.5 \mathrm{mV}$, Wilcoxon-Mann-Whitney two-sample rank test $P=0.2429$; Fig. $3 e)$. A change in action potential (AP) firing was recorded in 6 of 17 neurons to cooling stimuli (range $=-0.6$ to 3.6 APs per stimulus; Fig. 3f) and in 5 of 10 neurons to tactile stimuli (range $=-0.9$ to 10.5 APs per stimulus; Fig. 3f). There were more evoked APs during tactile than cooling stimulation (cooling, $n=17$ neurons, $0.53 \pm 0.20$ APs per stimulus; tactile, $n=10$ neurons, $2.24 \pm$ 0.94 APs per stimulus, Wilcoxon-Mann-Whitney two-sample rank test, $P=$ 0.0002; Fig. 3g). Measurements of the kinetics of the subthreshold responses in significantly responding neurons showed a longer latency (cooling, $202.6 \pm$ $72.4 \mathrm{~ms}, n=10$ neurons; tactile, $15.6 \pm 0.6 \mathrm{~ms}, n=7$ neurons, WilcoxonMann-Whitney two-sample rank test $P=0.0185$, Fig. 3h) and later time to peak (cooling, $925 \pm 155 \mathrm{~ms}, n=13$ neurons; tactile, $50.1 \pm 11.2 \mathrm{~ms}, n=7$ neurons, Wilcoxon-Mann-Whitney two-sample rank test $P<0.0001$ ) for cooling than for tactile stimulation (Fig. 3i), most likely explained by the faster kinetics and different amplitudes of tactile and thermal stimuli.

To have more control over stimulus presentation and paw movement during sensory stimulation, we next performed whole-cell recordings from layer $2 / 3$ cortical neurons under isoflurane anesthesia (Fig. 4a,b and Supplementary Fig. 2). Under isoflurane anesthesia, cortical neurons oscillate between hyperpolarized, quiescent "downstates" and depolarized, active "upstates". Stimulation of the paw elicited a subthreshold response to cooling in 11 of 16 neurons (range $=3.7-9.0 \mathrm{mV}$; Fig. 4c). We further tested ten of these neurons 
with a tactile stimulus and recorded a subthreshold response in all ten neurons (range = 5.7-20.1 mV; Fig. 4c). A comparison of the absolute evoked membrane potential responses showed a larger response to touch than to cooling (cooling, $n=16$ neurons, $5.64 \pm 0.46 \mathrm{mV}$; tactile, $n=10$ neurons, 12.0 $\pm 1.4 \mathrm{mV}$, Wilcoxon-Mann-Whitney two-sample rank test, $P=0.0001$; Fig. 4d). Only one cell showed a change in AP firing to cooling stimulation and none to tactile stimulation (Fig. 4e), highlighting the sparse coding of cortical neurons $\mathrm{L} 2 / 3$ under anesthesia ${ }^{24}$. Thus, there was no difference in the absolute numbers of evoked APs to cooling and tactile stimulation (cooling, $n=16$ neurons, $0.18 \pm 0.08$ APs per stimulus; tactile, $n=10$ neurons, $0.21 \pm 0.10$ APs per stimulus; Wilcoxon-Mann-Whitney two-sample rank test $P=0.4957$; Fig. 4f). The tactile stimulus had faster onset kinetics than the cold stimulus, which was reflected in the shorter latency (tactile, $23.6 \pm 5.9 \mathrm{~ms}, n=10$ neurons; cooling, $188.7 \pm 44.1 \mathrm{~ms}, n=10$ neurons, Wilcoxon-Mann-Whitney two-sample rank test $P<0.0001$; Fig. 4g) and the earlier time to peak (tactile, $91.4 \pm 32.5 \mathrm{~ms}, n=10$ neurons; cooling, $953.8 \pm 161.7 \mathrm{~ms}, n=11$ neurons; Wilcoxon-Mann-Whitney two-sample rank test $P<0.0001$; Fig. 4h) of the tactile compared to the cooling response. Simultaneous measurements of paw position confirmed that the paw did not move during thermal stimulation under anesthesia (Supplementary Fig. 3). L2/3 S1 forepaw cortex neurons are therefore multimodal for touch- and mild cold-evoked sensory input.

\section{S1 forepaw cortex is necessary for cooling perception}

We next assessed whether S1 has a causal role in thermal perception by silencing neuronal activity in S1 forepaw cortex during the sensory perception task with pharmacological microinjections. Tetrodotoxin (TTX) is a sodium channel antagonist that prevents action potential firing and can rapidly silence neuronal activity in vivo. Microinjection of TTX into forepaw S1 during the task robustly and reversibly reduced the detection of the cold thermal stimulus in six mice (Fig. 5a). TTX also prevents action potential firing in axons originating from neurons with somatic locations outside of S1. To avoid axonal inactivation, we next microinjected the AMPA receptor antagonists 6-cyano-7nitroquinoxaline-2,3-dione (CNQX) and NMDA receptor antagonist $D(-)-2-$ amino-5-phosphonovaleric acid (AP5). Injection of CNQX and AP5 into S1 
also blocked sensory perception of cooling stimuli in a reversible manner (Fig. $5 b)$; thus, glutamatergic transmission in forepaw S1 is required for cooling perception. Finally, we injected the $\mathrm{GABA}_{\mathrm{A}}$ receptor agonist muscimol to hyperpolarize and silence forepaw S1 neurons during the task. Muscimol injections also reduced the ability to detect cold thermal stimuli (Fig. 5c). Ringer's solution injection into forepaw S1 had no effect on thermal detection (Fig. 5d); thus, it was the pharmacological antagonists injected, and not the injection process itself, that blocked perception.

To confirm that the reduction in detection of cooling stimuli was not the result of the drugs spreading to other cortical or subcortical nuclei, we next injected TTX into primary visual cortex (V1) during the thermal detection task in trained mice. Injection of TTX into V1 in six mice had no effect on cold thermal detection (Fig. 5d). Recent work suggests that a cortical region near to forepaw S1 is associated with licking motor control ${ }^{25}$. To confirm that the inactivation of forepaw S1 had not also blocked the ability of mice to lick, we first inactivated forepaw S1 in three mice with TTX and noted that mice were still able to lick spontaneously. Furthermore, we trained four mice in an acoustic detection task and inactivated S1 forepaw cortex. Mice quickly learned to lick at short latency in response to a brief acoustic click. Inactivation of S1 forepaw cortex with TTX during the acoustic task did not affect the ability of the mouse to lick in response to an acoustic stimulus (Fig. $5 e)$. We therefore conclude that neuronal activity in forepaw S1 is necessary for mild cold thermal perception in mice.

\section{Cooling perception involves TRPM8}

Transient receptor potential melastatin 8 (TRPM8) has been identified as an ion channel receptor protein that mediates cold transduction in sensory afferent neurons that innervate the skin $^{26,27}$ and is involved in cold avoidance behavior in mice ${ }^{4-6,22}$. Whole-cell patch clamp recordings from $L 2 / 3$ cortical neurons in forepaw S1 in anaesthetized $\mathrm{Trpms}^{-/}$and $\mathrm{Trpms}^{+/+}$littermate control mice during cold thermal stimulation of the forepaw revealed that six of eight neurons in $\mathrm{Trpm}^{+/+}$mice showed a subthreshold response to cooling. In comparison, one of nine neurons in $\mathrm{Trpm}^{-/-}$mice responded to cooling (Fig. 
6a-c). The absolute evoked subthreshold response was significantly smaller in Trpm $^{-/-}$as compared to Trpm8 ${ }^{+/+}$mice $\left(\operatorname{Trpm}^{+/+}, 3.09 \pm 0.56 \mathrm{mV}, n=8\right.$ neurons; $\mathrm{Trpm}^{-/-}, 1.78 \mathrm{~ms} \pm 0.51 \mathrm{mV}, n=9$ neurons; Wilcoxon-MannWhitney two-sample rank test, $P=0.0333$; Fig. 6d). Trpm8 ${ }^{-/}$neurons did, however, respond to tactile stimulation of the paw (Supplementary Fig. 4). TRPM8 expression is therefore required for the response of S1 neurons to mild cooling stimuli of the paw.

Given that cortical neurons in $\mathrm{Trpm}^{-/-}$mice showed no cooling response, we predicted that these mice would be unable to learn the cooling detection task. We trained six Trpm $^{-/-}$and six littermate control Trpm $8^{+/+}$mice in the cooling detection task. Trpm $8^{+/+}$quickly learned the task, whereas $\operatorname{Trpm}^{-/-}$mice were unable to detect a $32-22^{\circ} \mathrm{C}$ cooling stimulus (Fig. 6e). $\mathrm{Trpm}^{-1-}$ mice did not have a major impairment in sensory learning, as mice that were unable to report cooling could report an acoustic stimulus after similar behavioral training (Supplementary Fig. 5). Our data suggest that the sensory afferent neurons expressing the TRPM8 receptor are the same neurons that provide the necessary afferent drive to cortical circuits in S1 that underpin the perception of mild cold in mice.

\section{C fibers signal mild cooling of the glabrous skin}

To identify which afferent fibers are responsible for forwarding cooling thermal information from glabrous skin to $S 1$, we made extracellular single-unit recordings from sensory afferents using an ex vivo skin-nerve preparation of the tibial nerve innervating the hind paw. Recordings in Trpm ${ }^{-/-}$and Trpm ${ }^{+/+}$ mice were made using 32-12 ${ }^{\circ} \mathrm{C}$ (Fig. 7a) and 32-22 ${ }^{\circ} \mathrm{C}$ stimuli (Supplementary Fig. 6) with a similar time course and shape as the stimuli used to train mice in the perceptual task. We reasoned that information on mild cooling that was absent in sensory afferents from $\operatorname{Trpm}^{-/-}$mice would allow us to pinpoint those fiber types that relay behaviorally relevant information to S1. Cooling of the skin can activate A- $\beta$ mechanoreceptors ${ }^{28}$ and $A-\delta$ and $C$ fiber afferents ${ }^{4,21-23}$, which are classically considered to be nociceptors ${ }^{29}$. Across all recordings, the percentage of afferents that responded to cold was reduced from 15.6\% (24 of 154 single units) in 
$\mathrm{Trpm}^{+/+}$mice to $5.7 \%$ (11 of 193 single units) in $\mathrm{Trpm}^{-/-}$mice (Chi-squared test, $P=0.0024$ ) (Supplementary Fig. 7a). A small proportion of A- $\beta$ mechanoreceptors respond to cooling in $\operatorname{Trpm}^{+/+}$mice $(-3.4 \%, 1$ of 29 units; Fig. 7b), albeit with relatively high thresholds (Fig. 7c). However, in Trpm8 ${ }^{-1-}$ mice, cooling-sensitive $A \beta$ mechanoreceptors were found at a similar frequency ( $10.4 \%, 5$ of 48 units, not significantly different from $\operatorname{Trpm}^{+/+}$mice, Fisher's exact test, $P=0.4002$ ) and with similar firing rates to control mice (Fig. 7b-d). A very small proportion of thinly myelinated, $A \delta$ fiber mechanonociceptors $(<5 \%)$ were activated by cooling, but again, there appeared to be little loss of cold sensitivity in A $\delta$ fibers recorded from TRPM8/- mice. Thus, the cold sensitivity of $A-\beta$ mechanoreceptors and A $\delta$ fibers seems unlikely to contribute to mild cooling perception in mice. In contrast, there was a significant reduction in the numbers (Fig $7 b, c)$ of $C$ fibers showing a response to cooling $\left(32-12{ }^{\circ} \mathrm{C}\right)$ in Trpm8 $^{-/-}$compared to control Trpm8 ${ }^{+/+}$ mice $\left(\operatorname{Trpm}^{+/+}\right.$mice, 30\%, 21 of 70 units tested; $\operatorname{Trpm}^{-/-}$mice, $7.6 \%, 5$ of 66 units; Chi-squared test, $P=0.0058)$, consistent with data from hairy skin ${ }^{4}$. Moreover, the firing rates were reduced in the remaining cold-responsive $C$ fibers in the TRPM $^{-/}$mouse (Fig. 7e).

Most cold sensitive $C$ fibers (19 of 21) were also responsive to mechanical stimuli (C-MCs), and the loss of Trpm8 led to a reduction in this population (Fig. 7c). The two cold sensitive $\mathrm{C}$ fibers lacking mechanosensitivity in Trpm $^{+/+}$mice showed no ongoing activity at rest and had cooling thresholds that were indistinguishable from other cold-sensitive $C$ fibers (Fig. 7). A subpopulation of low-threshold cold-sensitive $\mathrm{C}$ fibers also responded to noxious heat and were classified as C-MechanoHeatCold fibers (C-MHCs); we found no C-MHC fibers in Trpm8 ${ }^{-/-}$mice (Fig. 7c). The noxious heat sensitivity of $\mathrm{C}$ fibers was, however, unaltered in Trpm $8^{-1}$ mice (Supplementary Fig. 7). Examination of the cooling thresholds of the remaining cold sensitive $C$ fibers in $\mathrm{Trpm}^{-/-}$mice revealed that they had much higher cooling thresholds for activation than wild type receptors (mean threshold for all $\mathrm{C}$ fibers $(\mathrm{C}-\mathrm{MHC}+$ $\mathrm{C}-\mathrm{MC}), n=33$ in $13 \mathrm{Trpm}^{-/-}$mice, $18.0 \pm 1.8{ }^{\circ} \mathrm{C}$ from 13 mice, $23.9 \pm 0.8{ }^{\circ} \mathrm{C}$ for all identified C fibers; $n=3$ in $5 \mathrm{Trpm}^{+/+}$mice; Wilcoxon-Mann-Whitney two-sample rank test, $P=0.0202$; Fig. 7d). The behavioral performance of 
mice was reliable within $2{ }^{\circ} \mathrm{C}$ from baseline temperature (32-30 ${ }^{\circ} \mathrm{C}$ ) (Fig. 1); thus, our comparison of primary afferent recordings with sensory perception data indicates that TRPM8-expressing $C$ fiber nociceptors with low thresholds for cooling may relay behaviorally relevant information to S1. 


\section{DISCUSSION}

Our results reveal the neural circuits that enable mice to perceive cooling of the skin. We first found that mice were able to detect small cooling stimuli (2 ${ }^{\circ} \mathrm{C}$ from skin temperature) delivered to the forepaw, making their thermosensory performance similar to that of humans. Second, we found that mouse primary somatosensory forepaw cortex (S1) is necessary for thermal perception. Third, the TRPM8 cold receptor protein was necessary for mild cold temperature perception, suggesting that cold avoidance behaviors that are impaired in $\mathrm{Trpm}^{-/-}$mutant mice could be a result of a lack of fine temperature perception ${ }^{4-6}$. Finally, our primary sensory nerve recordings identified polymodal $C$ fibers with low thresholds for cooling as the likely drivers for fine cooling perception in mice.

The cortical responses to cold thermal stimulation suggest that forepaw S1 is directly involved in the perception of mild cold (Figs. 2-4). Using locally applied pharmacological reagents in forepaw S1 that block action potentials and synaptic transmission or enhance inhibition, we found that cooling detection performance was reversibly blocked (Fig. 5). We conclude that forepaw S1 is necessary for mild cold thermal perception. Previous studies in humans have shown that patients with lesions in S1 can have deficits in thermal perception threshold ${ }^{30-32}$, and intracortical stimulation can elicit illusory thermal sensations of the skin $^{33,34}$. Furthermore, neuronal responses to thermal stimulation have been recorded in $\mathrm{S} 1$ in humans ${ }^{35}$, cats $^{36,37}$ and monkeys $^{38}$. More recently, however, lesion studies ${ }^{39,40}$, cortical stimulation ${ }^{41}$, magnetoencephalographic ${ }^{42}$ and functional magnetic resonance imaging ${ }^{43}$ has led to the suggestion that insular cortex has a major role in non-noxious thermal perception in humans. Our data suggest that $\mathrm{S} 1$ is critical for thermal perception in mice, but do not exclude a role of insular cortex for thermal processing. Indeed, in rodents, a secondary somatosensory representation is located in insular cortex ${ }^{44}$.

It is now well established that the TRPM8 ion channel present in sensory afferents is an important transducer of cold ${ }^{4-6,27}$. We found that $\mathrm{Trpm}^{-/-}$ 
mutant mice are incapable of perceiving mild cold and this lack of behavior is correlated with the loss of cold-evoked activity in cortical L2/3 neurons. It has been shown that, in hairy skin, deletion of the Trpms gene reduces the number of cold sensitive fibers ${ }^{4}$. We confirmed and extended these findings by showing that the major cell population that responded to rapid mild cooling stimulation of glabrous skin and showed a reduction in numbers and threshold in the $\mathrm{Trpm}^{-/-}$mouse were of polymodal C fibers. Support for this idea comes from the fact that the majority of cold-evoked activity in L2/3 cortical neurons was evoked with long latencies, consistent with the very long conduction time of $\mathrm{C}$ fibers. Some cold-evoked responses may also derive from cold-sensitive A $\delta$ fibers ${ }^{45}$, but this probably represents a sparse sensory drive, as robust increases in $\mathrm{A} \delta$ fiber thermal thresholds were not observed in $\operatorname{Trpm}^{-/}$mice. These data raise the possibility that behaviorally relevant sensory information related to the haptic properties of felt objects from the glabrous skin may be signaled by classical nociceptors.

It makes intuitive sense that touch and temperature input are processed by the same cortical region as the feel of an object is inseparable from its thermal conductivity. This fact is illustrated by well-known perceptual illusions like Weber's effect, where cold objects feel heavier than neutral objects and a warm penny placed on the skin next to a cold penny also feels $\operatorname{cold}^{46,47}$. An intriguing observation from our cortical recordings is that individual L2/3 S1 forepaw cortex neurons are activated by both tactile and cold thermal stimulation of the paw in awake and anesthetized mice (Figs. 3 and 4). Although the peak evoked membrane potential response to cold stimulation was smaller (about half) than that to tactile, this could reflect the different onset kinetics of the stimuli. The slower and less synchronized afferent drive during thermal stimulation could cause a temporal smearing of the synaptic response in cortex and reduced amplitude as compared with faster onset tactile stimuli with more synchronized afferent input. Reminiscent of membrane potential and optical recordings from L2/3 neurons in other cortical regions ${ }^{24}$, we observed sparse, heterogeneous spiking responses to thermal and tactile stimulation. It is known that neurons in primary sensory cortical regions do integrate sensory input across modalities ${ }^{48-50}$; however, these 
interactions are typically studied between modalities transduced by different sense organs such as sound and vision. We found multimodal responses in the same cortical region from separate sensory pathways originating at the same sense organ, the glabrous skin. Our results therefore establish a genetic model system for investigating not only thermal perception, but also the integration of multimodal sensory input in the formation of a unified sensory percept, a fundamental operation of the neocortex.

\section{Supplementary Information}

Supplementary Information contains 7 figures and is located after Online Methods. 


\section{REFERENCES}

1. Frenzel, H. et al. A genetic basis for mechanosensory traits in humans. PLoS Biol. 10, e1001318 (2012).

2. Johnson, K. O., Darian-Smith, I. \& LaMotte, C. Peripheral neural determinants of temperature discrimination in man: a correlative study of responses to cooling skin. J. Neurophysiol. 36, 347-370 (1973).

3. McKemy, D. D. The molecular and cellular basis of cold sensation. ACS Chem. Neurosci. 4, 238-247 (2013).

4. Bautista, D. M. et al. The menthol receptor TRPM8 is the principal detector of environmental cold. Nature 448, 204-208 (2007).

5. Dhaka, A. et al. TRPM8 Is Required for Cold Sensation in Mice. Neuron 54, 371-378 (2007).

6. Colburn, R. W. et al. Attenuated Cold Sensitivity in TRPM8 Null Mice. Neuron 54, 379-386 (2007).

7. Feldmeyer, D. et al. Barrel cortex function. Prog. Neurobiol. 103, 3-27 (2013).

8. Diamond, M. E. \& Heimendahl, von, M. 'Where' and 'what' in the whisker sensorimotor system. Nat. Rev. Neurosci. 9, 601-612 (2008).

9. Sachidhanandam, S., Sreenivasan, V., Kyriakatos, A., Kremer, Y. \& Petersen, C. C. H. Membrane potential correlates of sensory perception in mouse barrel cortex. Nat. Neurosci. 16, 1671-1677 (2013).

10. Guo, Z. V. et al. Flow of cortical activity underlying a tactile decision in mice. Neuron 81, 179-194 (2014).

11. Miyashita, T. \& Feldman, D. E. Behavioral detection of passive whisker stimuli requires somatosensory cortex. Cereb. Cortex 23, 1655-1662 (2013).

12. Hutson, K. A. \& Masterton, R. B. The sensory contribution of a single vibrissa's cortical barrel. J. Neurophysiol. 56, 1196-1223 (1986).

13. Kleinfeld, D. \& Deschênes, M. Neuronal basis for object location in the vibrissa scanning sensorimotor system. Neuron 72, 455-468 (2011).

14. Finger, S. \& Frommer, G. P. Effects of cortical and thalamic lesions on temperature discrimination and responsiveness to foot shock in the rat. 
Brain Res. 24, 69-89 (1970).

15. Finger, S., Scheff, S., Warshaw, I. \& Cohen, K. Retention and acquisition of fine temperature discriminations following somatosensory cortical lesions in the rat. Exp. Brain Res. 10, 340-346 (1970).

16. Downer, J. \& Zubek, J. P. Role of the cerebral cortex in temperature discrimination in the rat. J. Comp. Physiol. Psychol. 47, 199-203 (1954).

17. Porter, L. H., Hecht, G. S. \& Sheaffer, R. Disturbances in the performance of thermal discrimination tasks following cortical ablations in rats. Brain Res. 621, 319-330 (1993).

18. Hellon, R. F., Misra, N. K. \& Provins, K. A. Neurones in the somatosensory cortex of the rat responding to scrotal skin temperature changes. J. Physiol. (Lond.) 232, 401-411 (1973).

19. Duclaux, R. \& Kenshalo, D. R. The temperature sensitivity of the type I slowly adapting mechanoreceptors in cats and monkeys. J. Physiol. (Lond.) 224, 647-664 (1972).

20. Schepers, R. J. \& Ringkamp, M. Thermoreceptors and thermosensitive afferents. Neuroscience \& Biobehavioral Reviews 33, 205-212 (2009).

21. Campero, M., Serra, J., Bostock, H. \& Ochoa, J. L. Slowly conducting afferents activated by innocuous low temperature in human skin. $J$. Physiol. (Lond.) 535, 855-865 (2001).

22. Zimmermann, K. et al. Transient receptor potential cation channel, subfamily $\mathrm{C}$, member 5 (TRPC5) is a cold-transducer in the peripheral nervous system. Proc. Natl. Acad. Sci. U.S.A. 108, 18114-18119 (2011).

23. Noël, J. et al. The mechano-activated $\mathrm{K}+$ channels TRAAK and TREK-1 control both warm and cold perception. EMBO J. 28, 1308-1318 (2009).

24. Barth, A. L. \& Poulet, J. F. A. Experimental evidence for sparse firing in the neocortex. Trends Neurosci. 35, 345-355 (2012).

25. Komiyama, T. et al. Learning-related fine-scale specificity imaged in motor cortex circuits of behaving mice. Nature 464, 1182-1186 (2010).

26. McKemy, D. D., Neuhausser, W. M. \& Julius, D. Identification of a cold receptor reveals a general role for TRP channels in thermosensation. Nature 416, 52-58 (2002).

27. Peier, A. M. et al. A TRP channel that senses cold stimuli and menthol. 
Cell 108, 705-715 (2002).

28. Knibestöl, M. \& Vallbo, A. B. Single unit analysis of mechanoreceptor activity from the human glabrous skin. Acta Physiol. Scand. 80, 178195 (1970).

29. Lewin, G. R. \& Moshourab, R. Mechanosensation and pain. J. Neurobiol. 61, 30-44 (2004).

30. Marshall, J. Sensory disturbances in cortical wounds with special reference to pain. J. Neurol. Neurosurg. Psychiatr. 14, 187-204 (1951).

31. Veldhuijzen, D. S., Greenspan, J. D., Kim, J. H. \& Lenz, F. A. Altered pain and thermal sensation in subjects with isolated parietal and insular cortical lesions. Eur. J. Pain 14, 535.e1-11 (2010).

32. Adams, R. W. \& Burke, D. Deficits of thermal sensation in patients with unilateral cerebral lesions. Electroencephalogr. Clin. Neurophysiol. 73, 443-452 (1989).

33. Cushing, H. A note upon the faradic stimulation of the postcentral gyrus in conscious patients. Brain 32, 44-53 (1909).

34. Penfield, W. \& Boldrey, E. Somatic motor and sensory representation in the cerebral cortex of man as studied by electrical stimulation. Brain 60 , 389-443 (1937).

35. Duclaux, R., Franzen, O., Chatt, A. B., Kenshalo, D. R. \& Stowell, H. Responses recorded from human scalp evoked by cutaneous thermal stimulation. Brain Res. 78, 279-290 (1974).

36. Landgren, S. Cortical reception of cold impulses from the tongue of the cat. Acta Physiol. Scand. 40, 202-209 (1957).

37. Tsuboi, Y. et al. Response properties of primary somatosensory cortical neurons responsive to cold stimulation of the facial skin and oral mucous membrane. Brain Res. 613, 193-202 (1993).

38. Kreisman, N. R. \& Zimmerman, I. D. Representation of information about skin temperature in the discharge of single cortical neurons. Brain Res. 55, 343-353 (1973).

39. Birklein, F., Rolke, R. \& Müller-Forell, W. Isolated insular infarction eliminates contralateral cold, cold pain, and pinprick perception. Neurology 65, 1381 (2005).

40. Cattaneo, L., Chierici, E., Cucurachi, L., Cobelli, R. \& Pavesi, G. 
Posterior insular stroke causing selective loss of contralateral nonpainful thermal sensation. Neurology 68, 237 (2007).

41. Mazzola, L., Isnard, J., Peyron, R. \& Mauguière, F. Stimulation of the human cortex and the experience of pain: Wilder Penfield's observations revisited. Brain 135, 631-640 (2012).

42. Maihöfner, C., Kaltenhäuser, M., Neundörfer, B. \& Lang, E. Temporospatial analysis of cortical activation by phasic innocuous and noxious cold stimuli--a magnetoencephalographic study. Pain 100, 281-290 (2002).

43. Craig, A. D., Chen, K., Bandy, D. \& Reiman, E. M. Thermosensory activation of insular cortex. Nat. Neurosci. 3, 184-190 (2000).

44. Rodgers, K. M., Benison, A. M., Klein, A. \& Barth, D. S. Auditory, somatosensory, and multisensory insular cortex in the rat. Cereb. Cortex 18, 2941-2951 (2008).

45. Mackenzie, R. A., Burke, D., Skuse, N. F. \& Lethlean, A. K. Fibre function and perception during cutaneous nerve block. J. Neurol. Neurosurg. Psychiatr. 38, 865-873 (1975).

46. Green, B. G. Localization of thermal sensation: An illusion and synthetic heat. Perception \& Psychophysics 22, 331-337 (1977).

47. Stevens, J. C. \& Green, B. G. Temperature-touch interaction: Weber's phenomenon revisited. Sensory Processes 2, 206-209 (1978).

48. Lurilli, G. et al. Sound-driven synaptic inhibition in primary visual cortex. Neuron 73, 814-828 (2012).

49. Senkowski, D., Schneider, T. R., Foxe, J. J. \& Engel, A. K. Crossmodal binding through neural coherence: implications for multisensory processing. Trends Neurosci. 31, 401-409 (2008).

50. Saleem, A. B., Ayaz, A., Jeffery, K. J., Harris, K. D. \& Carandini, M. Integration of visual motion and locomotion in mouse visual cortex. Nat. Neurosci. 16, 1864-1869 (2013).

\section{Acknowledgements}


We thank J. König for technical assistance, J.-S. Jouhanneau for help with cell reconstruction, L. Estebanez for programming advice, and L. Estebanez and $E$. Bobrov for constructive comments on a previous version of the manuscript. This work was funded by grants from the European Research Council (ERC-2010-StG-260590, J.F.A.P.; ERC-2011-StG-280565, J.S.) and the Deutsche Forschungs Gemeinschaft (Exc 257 NeuroCure and DFG-FOR1341 BaCoFun, J.F.A.P.; Collaborative Research Center 665 Project B6, G.R.L.). Additional support was obtained from a Bernstein Center for Computational Neuroscience grant from the BMBF (01GQ1001E, G.R.L.).

Deutsche Forschungs Gemeinschaft (Exc 257 NeuroCure and BaCoFun) (J.F.A.P.), the EU (FP7-ICT 3X3D) (J.F.A.P.) collaborative research center 665 project grant (G.R.L.), European Research Council (ERC) starting grants (J.F.A.P., J.S.) and an ERC senior grant (G.R.L.). Additional support was obtained from a Bernstein Center for Computational Neuroscience grant from the BMBF (G.R.L.).

\section{Author contribution}

N.M., J.F.A.P. and G.R.L. designed the project. N.M. performed and analyzed behavioral training, intrinsic optical imaging, whole-cell recordings and pharmacological inactivation. W-J.Z. performed whole-cell recordings. J.W. performed and analyzed afferent recordings. T.A. wrote code and performed behavioral training. J.S. provided reagents and the TRPM8 mice. J.F.A.P. and G.R.L. supervised the project and wrote the manuscript. 


\section{FIGURE LEGENDS}

Figure 1. Mice can perceive mild cooling of the forepaw. a, Schematic of behavioral training setup; the forepaw digits were stimulated with a Peltier element. b, Mice received water rewards if they licked during the window of opportunity after a stimulus (hit). Stimulus trials and catch trials were interleaved. c, Mice rapidly learned to report cooling stimuli and progressively increased the probability of hits $(P($ lick $))$ during once per day training sessions (ANOVA with Tukey's multiple comparison: day $1, P=0.0232$; day $2, P=$ 0.0326; day $3, P=0.0045$; day $4, P<0.0001$; day $5, P<0.0001$; day $6, P<$ $0.0001 ; n=10$ mice). $\mathbf{d}$, The cooling perceptual threshold was tested in trained mice by reducing the amplitude of the cooling stimulus from the $32^{\circ} \mathrm{C}$ hold temperature by different amounts in daily sessions (ANOVA with Tukey's multiple comparison: $10{ }^{\circ} \mathrm{C}, P=0.0005 ; 6{ }^{\circ} \mathrm{C}, P=0.0003 ; 4{ }^{\circ} \mathrm{C}, P=0.0039 ; 2$ ${ }^{\circ} \mathrm{C}, P=0.0100 ; 1{ }^{\circ} \mathrm{C}, P=0.1242 ; 0.75{ }^{\circ} \mathrm{C}, P=0.1048 ; 0.5^{\circ} \mathrm{C}, P=0.1207 ; n=$ 6 mice). In $\mathbf{c}$ and $\mathbf{d}$, data points indicate population mean and error bars represent the s.e.m. Asterisks represent significance between hit and false licks, ${ }^{*}=P<0.05,{ }^{* *} P<0.01,{ }^{* *} P<0.001$.

Figure 2. Intrinsic optical imaging reveals overlapping cooling and touch responses in forepaw somatosensory cortex. a, Example intrinsic optical imaging signal under isoflurane anesthesia to cooling thermal stimulation (32$18{ }^{\circ} \mathrm{C}$ ) of the forepaw. $\mathbf{b}$, Intrinsic optical image response to tactile stimulation of the forepaw from the same mouse. c, Image of the skull overlaid with $80 \%$ of the response area to the cooling (cyan) and tactile (orange) stimuli from (b) and (c). d, Overlay of the $80 \%$ response areas from eight mice centered on the highest intensity value of the tactile response (orange dot) shows the response area overlap and the location of the peak cold response (blue dots).

Figure 3. Whole-cell recordings from L2/3 neurons in forepaw S1 of awake mice reveal responses to cooling and tactile stimuli. a, Example whole-cell recording from a L2/3 cortical neuron showing (above) single trial and (below) averaged responses to cooling of the forepaw. Horizontal marks indicate $-70 \mathrm{mV}$. b, c, A second example cell from a different mouse showing both cooling (b) and tactile (c) responses to stimulation of the forepaw. 
Horizontal marks indicate $-60 \mathrm{mV}$. d, Evoked subthreshold responses of individual cells to cooling (cyan) and tactile (orange), with significantly responding cells shown in color and non-significant in gray (cool, $n=17$ cells from 15 mice; tactile, $n=10$ cells from 7 mice). e, Population analysis of the absolute amplitude of the evoked response to cooling and tactile stimulation (cool, $n=17$ cells from 15 mice; tactile, $n=10$ cells from 7 mice). f, Evoked action potential firing to cooling and tactile stimulation with significant responses shown in color and non-significant responses shown in gray (cool, $n=17$ cells from 15 mice; tactile, $n=10$ cells from 7 mice). $\mathbf{g}$, Population analysis of absolute evoked firing to cooling and tactile stimulation (cool, $n=$ 17 cells from 15 mice; tactile, $n=10$ cells from 7 mice). $\mathbf{h}, \mathrm{L} 2 / 3$ neurons responded with a shorter latency to tactile stimulation than thermal stimuli (cool, $n=10$ cells from 8 mice; tactile, $n=7$ cells from 7 mice). i, Time to peak of the evoked response to cooling and tactile stimulation (cool, $n=13$ cells from 11 mice; tactile, $n=7$ cells from 7 mice). In e and $\mathbf{g}-\mathbf{i}$, the bars indicate the population mean and error bars represent s.e.m., and individual cells are marked as circles. In $\mathbf{h}$ and $\mathbf{i}$, open circles represent the individual data points from significantly responding cells.

Figure 4. Whole-cell recordings from L2/3 forepaw S1 neurons during cooling and tactile stimulation in isoflurane anesthetized mice. $a, b$, Example whole-cell recording from a $L 2 / 3$ cortical neuron showing single trial sensory responses to cooling $\left(32-22{ }^{\circ} \mathrm{C}\right.$, blue, a) and vibrotactile $(100 \mathrm{~Hz}$, orange, b) stimulation of the forepaw at different time scales with averaged membrane potential responses and peri-stimulus time histograms (PSTH) shown below. Horizontal marks represent $-60 \mathrm{mV}$. c, Evoked subthreshold response amplitude from individual cells (cool, $n=16$ cells from 11 mice; tactile, $n=10$ cells from 8 mice). d, Population absolute evoked peak response during cooling and tactile stimulation of the forepaw (cool, $n=16$ cells from 11 mice; tactile, $n=10$ cells from 8 mice). e, Evoked action potentials from individual cells (cool, $n=16$ cells from 11 mice; tactile, $n=10$ cells from 8 mice). f, Population absolute evoked action potential firing showed no significant difference between cooling and tactile stimulation (cool, $n=16$ cells from 11 mice; tactile, $n=10$ cells from 8 mice). $\mathbf{g}, \mathbf{h}$, Subthreshold 
responses to cooling had a longer latency (cool, $n=10$ cells from 8 mice; tactile, $n=10$ cells from 8 mice; $\mathbf{g}$ ) and later time to peak (cool, $n=11$ cells from 9 mice; tactile, $n=10$ cells from 9 mice; $\mathbf{h}$ ) than during tactile stimulation. Bars indicate mean population and error bars represent s.e.m. Gray points are non-significant responses.

Figure 5. Pharmacological inactivation of forepaw primary somatosensory cortex prevents cooling perception. a-c, Microinjection of TTX (a), CNQXIAP5 (b) and muscimol (c) into forepaw S1 prevented perception of the cooling stimulus (pre versus TTX, $n=6$ mice, ANOVA with Tukey's multiple comparison $P=0.0064$; pre versus CNQXIAP5, $n=6$ mice, ANOVA with Tukey's multiple comparison $P=0.0283$; pre versus muscimol, $n$ $=6$ mice, paired $t$ test, $P=0.0002)$. d, Injection of extracellular Ringer's solution into S1 or TTX into primary visual cortex (V1) did not alter cooling perception (pre versus Ringer's, $n=6$ mice, ANOVA with Tukey's multiple comparison, $P=0.8174$; Ringer's versus V1 TTX, $n=6$ mice, ANOVA with Tukey's multiple comparison, $P>0.9999$; pre versus V1 TTX, $n=6$ mice, ANOVA with Tukey's multiple comparison, $P=0.9975)$. e, TTX injection into forepaw S1 did not affect the ability of mice to report an acoustic stimulus with licking (pre versus TTX, $n=4$ mice, paired $t$ test, $P=0.9307$ ). Cyan lines show hit response rates and black lines show false hits. Data points indicate mean population and error bars represent s.e.m. $n s=$ not significant $(P>$ 0.05).

Figure 6. $\operatorname{Trpm}^{-1-}$ mice are unable to report cooling of the forepaw and have reduced cortical responses to cooling. a, b, Example whole-cell recordings from L2/3 cortical neurons in a $\operatorname{Trpm}^{-/}$(a, magenta) and a $\mathrm{Trpm}^{+/+}$(b, cyan) littermate control mouse showing single trials (above) and averaged response (below) to cooling stimulation. Horizontal marks on $V_{m}$ represent $-60 \mathrm{mV}$ for $\mathrm{Trpm}^{-/-}$and $-50 \mathrm{mV}$ for $\mathrm{Trpm}^{+/+}$. c, Open circles show individual cell responses to cooling, colored circles show significant responses and gray circles show non-significant responses $(n=8$ cells from 7 $\mathrm{Trpm}^{\mathrm{H} /+}$ mice, 9 cells from $9 \mathrm{Trpm}^{-/-}$mice). d, Population analysis of the absolute evoked sensory response revealed that cortical neurons in $\operatorname{Trpm}^{+/+}$ mice showed a larger subthreshold response to cooling than those in $\mathrm{Trpm}^{-/-}$ 
mice $\left(n=8\right.$ cells from $7 \mathrm{Trpm}^{+/+}$mice, 9 cells from $9 \mathrm{Trpm}^{\mathrm{O}^{-/}}$mice; Wilcoxon-Mann-Whitney two-sample rank test, $P=0.033$ ). e, Behavioral training in a cooling $\left(32-22{ }^{\circ} \mathrm{C}\right)$ detection task revealed that $\mathrm{Trpm}^{-/-}$mice (magenta) were unable to learn the task, whereas littermate $\operatorname{Trpm}^{+/+}$quickly showed improved success rates over daily training sessions (day 6: (hit-fail rate) $\operatorname{Trpm}^{+/+}$versus (hit-fail rate) $\operatorname{Trpm}^{-/-}, n=6$ mice, ANOVA with Tukey's multiple comparison, $P<0.0001$ ). Bars in $\mathbf{d}$ and $\mathbf{e}$ represent mean population and error bars represent s.e.m.

Figure 7. Trpm8 expressing afferent neurons drive mild cold perception. a, Example recordings from cutaneous $\mathrm{C}$ fibers in $\mathrm{Trpm}^{+/+}$(cyan) and Trpm8 ${ }^{-}$ ${ }^{/-}$(magenta) mice during cold stimulation $\left(32-12{ }^{\circ} \mathrm{C}\right.$ ). Colored APs selected for analysis using a spike sorting algorithm are shown on right; gray spikes were discarded. $\mathbf{b}$, Incidence of different fiber types responding to cold stimulation in $\mathrm{Trpm}^{+/+}$and $\mathrm{Trpm}^{-/-}$from a survey experiment in which all fibers recorded were included in the data set; note the reduction in cold sensitive $C$ fibers in the $\operatorname{Trpm}^{-/-}$mouse. c, Graph showing that the threshold temperature of the first spike was reduced in C-MHC and C-MC fibers from a data set that included units identified by their cold response. Gray points highlight two coldspecific $C$ fibers that did not respond to mechanical stimulation. Bars represent mean population and error bars represent s.e.m. d, The entire population of cold-sensitive A fibers in $\operatorname{Trpm}^{+/+}$(8 fibers from 13 mice) and Trpm $^{-/-}$(10 fibers from 5 mice) mice showed little difference in firing rates during the cooling stimulus. e, In contrast, in Trpm ${ }^{+/+}$mice, C-MC (21 fibers from 13 mice) and C-MHC (12 fibers from 13 mice) fibers fired as a function of stimulus amplitude, but, in the Trpm $8^{-/}$mouse, C-MC fibers (3 fibers from 5 mice) showed a reduced firing rate. No C-MHC fibers were identified in the Trpm $^{-/-}$mouse. 


\section{ONLINE METHODS}

All experimental procedures were carried out in accordance with the State of Berlin Animal Welfare requirements and were approved by this authority.

\section{Preparation of mice and surgery.}

To implant a head support, 4-8-week-old male C57BL6J and male and female Trpm $^{-/-4}$ and Trpm8 ${ }^{+/+}$P28-60 mice were anesthetized with isoflurane (1.5\%-2\% in $\mathrm{O}_{2}$ ) and injected with $200 \mathrm{mg}$ per $\mathrm{kg}$ body weight Metamizol. Eye blink and paw withdrawal reflexes were absent. Mice were constantly heated to $37{ }^{\circ} \mathrm{C}$ with a heating blanket and rectal probe. A lightweight metal head support was implanted onto the skull with glue (UHU dent) and dental cement (Paladur). Mice were then placed in their home cage to recover from surgery with $200 \mathrm{mg}$ Metamizol per $\mathrm{ml}$ in the drinking supply.

\section{Intrinsic optical imaging and craniotomy.}

Intrinsic optical imaging was performed to image responses to tactile and thermal stimuli and locate S1 forepaw cortex for whole-cell recordings. Briefly, the skull was covered with warmed Ringer's solution containing $135 \mathrm{mM} \mathrm{NaCl}$, $5 \mathrm{mM} \mathrm{KCl}, 5 \mathrm{mM}$ HEPES, $1.8 \mathrm{mM} \mathrm{CaCl}_{2}$ and $1 \mathrm{mM} \mathrm{MgCl}$ and illuminated with red light $(630 \mathrm{~nm})$. To locate the intrinsic signal response to somatosensory stimulation of the paw, Digit 3 was repeatedly stimulated either with a tactile (piezo stimulator at $10 \mathrm{~Hz}$ for $8 \mathrm{~s}$ ), or a 3-s cooling stimulus (32-18 ${ }^{\circ} \mathrm{C}$ with a Peltier element). The intrinsic signal and the blood vessel pattern, seen under green illumination $(530 \mathrm{~nm})$, were then used to locate forepaw S1. Intrinsic optical imaging was made with a monochrome QIcam CCD camera (QImaging). For whole-cell recordings or pharmacological microinjections, we next made a small diameter $(<1 \mathrm{~mm})$ craniotomy over forepaw S1. The dura was left intact for pharmacological injections, but carefully removed for whole-cell recordings with a needle. The brain was covered in Kwick-Cast (WPI) between surgery and recording.

\section{Whole-cell recordings and sensory stimulation.}


Whole cell patch-clamp recordings were made with 2-mm borosilicate glass (Hilgenberg) filled with intracellular solution containing $135 \mathrm{mM}$ potassium gluconate, $4 \mathrm{mM} \mathrm{KCl}, 10 \mathrm{mM}$ HEPES, $10 \mathrm{mM}$ sodium phosphocreatine, $4 \mathrm{mM}$ MgATP, $0.3 \mathrm{mM} \mathrm{Na}{ }_{3} \mathrm{GTP}$ (adjusted to $\mathrm{pH} 7.3$ with $\mathrm{KOH}$ ) and $2 \mathrm{mg} \mathrm{ml}^{-1}$ biocytin. Whole-cell recordings were made from an Axon Multiclamp 700b amplifier (Molecular Devices) in current-clamp mode. The brain was covered with Ringer's solution and an $\mathrm{Ag} / \mathrm{AgCl}$ ground electrode was placed in the recording chamber. For anesthetized whole-cell recordings, mice were isoflurane anesthetized (about $1 \%$ in $\mathrm{O}_{2}$ ). Blind whole-cell recordings were made from L2/3 (<450 $\mu \mathrm{m}$ from pial surface) cortical neurons. Pipettes were inserted into forepaw S1 normal to cortical surface under high pressure (100$150 \mathrm{mBar}$ ) that was reduced to 20-30 mBar for approaching a cell. One 3-s cooling stimulus (0.5-s onset ramp, 2-s hold, 0.5-s offset ramp) and a 300-ms (1.5-ms onset and offset ramps), $100-\mathrm{Hz}$ sine wave tactile stimuli were delivered every $20 \mathrm{~s}$. Recordings were digitized at $20 \mathrm{kHz}$, high pass filtered at $10 \mathrm{kHz}$ and recorded via an ITC-18 (Heka) analog to digital interface board connected to a PC under the control of homemade scripts written in IgorPro (Wavemetrics).

For awake patch whole-cell patch-clamp recordings, methods were similar to those previously described ${ }^{51}$. Mice were gradually adapted to head-fixation and paw-tethering over a period of $3 \mathrm{~d}$. Alongside cushioning, insulation paper was used to tether the right forepaw. Intrinsic imaging and the craniotomy were performed on the day of experiment and mice recovered from anesthesia for at least $4 \mathrm{~h}$ before recording. Thermal stimulation was performed with a 3- x 3-mm Peltier element stimulator (Yale Medical School). A force-feedback mechanical stimulator (Aurora Scientific, Dual-Mode Lever Arm systems 300-C) was used to deliver tactile stimuli and measure paw movements.

\section{Histology.}

Following every experiment, mice were deeply anesthetized by intraperitoneal injection of $2.5 \mathrm{~g}$ per $\mathrm{kg}$ body weight urethane and then transcardially perfused with $4 \%$ paraformaldehdye (PFA, wt/vol). The brain was removed, 
fixed in 4\% PFA overnight and then stored in phosphate buffer before histological processing. The brain was sliced into $100-\mu \mathrm{m}$-thick slices tangential to forepaw S1 using a Leica VT1000 S vibrating microtome. Slices were stained for cytochrome oxidase and then biocytin with a standard $A B C$ kit (Vectastain) with DAB enhancement. Slices were mounted in Moviol and stored at $4{ }^{\circ} \mathrm{C}$. Neurons were photographed and reconstructed using NeuroLucida software (MicroBrightField).

\section{Behavioral training and pharmacological microinjections.}

Mice were water restricted and weight monitored and kept on a normal light/dark cycle. Behavioral training involved a first period of habituation to head-restraint with free access to water from the water spout. Next, mice received automatic water rewards paired to presentation of the cooling stimulus to build an association between cooling and reward for $2 \mathrm{~d}$. Initial 1 or 2 training sessions were done without a time out. Afterwards a time out was introduced and this session is considered as the first session for the lick rate analysis. Catch trials were included as $50 \%$ of the total trials from the start of training. All trials were delivered at randomized time intervals between 5 and $15 \mathrm{~s}$. Mice received a water reward (4-7 $\mu \mathrm{l})$ if they licked within a 3-s window of opportunity from the start of the stimulus. A typical training session lasted about 40 min with about 240 (120 stim + 120 catch) total trials and was performed once per day. An identical training procedure was used during acoustic training. The acoustic stimulus was a 5-ms click generated by an electronic valve. Behavioral training was performed and data collected using custom-written routines in Lab View at 1-kHz sampling rate.

Before pharmacological inactivation of the cortex, mice were trained with cooling stimuli for at least $7 \mathrm{~d}$. Pharmacological microinjections were performed with a broken glass (diameter about $20 \mu \mathrm{m}$ ) thin-walled glass micropipette and an oil hydraulic injection system (MO-10, Narashige). The drugs were injected into (700- $\mu \mathrm{m}$-depth single injection of $100 \mathrm{nl}$ TTX or multiple injections into 1000, 800, 600, 400 and $200 \mu \mathrm{m}, 100 \mathrm{nl}$ each over 15 min for CNQX-AP5 and Muscimol). Drugs had concentrations of: TTX (20 $\mu \mathrm{M})$, 
CNQXIAP5 $(200 \mu \mathrm{M} / 500 \mu \mathrm{M})$, Muscimol (10 mM). Behavioral performance was assessed 10 or 40 mins from the end of injection.

\section{Skin-nerve preparation and sensory afferent recordings.}

We used a modified ex vivo skin nerve preparation in which we recorded from single units in the tibial nerve that innervate the glabrous plantar surface of the hind limb. Recordings from single units were made as previously described $^{52,53}$, however, we applied cooling stimuli (Peltier device) with almost identical amplitudes and kinetics to those employed in behavioral training paradigms and cortical recordings. Two cooling ramps were routinely applied, $32-22{ }^{\circ} \mathrm{C}$ to probe for low-threshold units and a second $32-12{ }^{\circ} \mathrm{C}$ stimulus to characterize high-threshold responders and suprathreshold firing of coldsensitive fibers. All the $\mathrm{C}$ fibers recorded could be classified as nociceptors based on their high mechanical thresholds $(>2 \mathrm{mN})$ and sustained firing to the static phase of a ramp and hold force stimulus.

The hind limb sole of foot skin innervated by the tibial, medial and lateral plantar nerve was removed leaving the nerve intact. The skin was then placed in a heated (32 ${ }^{\circ} \mathrm{C}$ ) organ bath and fixed epidermis-side up using insect needles while the nerve was transferred via a narrow channel into an adjacent chamber filled with mineral oil for nerve teasing and single-fiber recordings. The organ bath chamber was constantly perfused with oxygen-saturated synthetic interstitial fluid consisting of $123 \mathrm{mM} \mathrm{NaCl}, 3.5 \mathrm{mM} \mathrm{KCl}, 0.7 \mathrm{mM}$ $\mathrm{MgSO}_{4}, 1.7 \mathrm{mM} \mathrm{NaH} \mathrm{PO}_{4}, 2.0 \mathrm{mM} \mathrm{CaCl}$, $9.5 \mathrm{mM}$ sodium gluconate, 5.5 $\mathrm{mM}$ glucose, $7.5 \mathrm{mM}$ sucrose and $10 \mathrm{mM}$ HEPES, 10 at a $\mathrm{pH}$ of 7.4. To ensure a sufficient supply of oxygenated buffer to the dermis, fresh buffer was applied regularly below the skin using a 1-ml pipette. Single mechanicalsensitive units were identified using a glass rod and classified by their conduction velocity and mechanical threshold as described previously ${ }^{54}$. A Peltier element-based contact probe applying thermal stimuli (custom device built by the Yale School of Medicine Instrumentation Repair and Design, as for in vivo experiments) was used to identify and classify heat- or coldsensitive units. For cooling a mild stimulus $\left(32-22{ }^{\circ} \mathrm{C}\right.$ in $1.3 \mathrm{~s}$ and hold for $\left.2 \mathrm{~s}\right)$ 
for cold a strong stimulus $\left(32-12{ }^{\circ} \mathrm{C}\right.$ in $\left.7 \mathrm{~s}\right)$, for warmth a mild $\left(32-42{ }^{\circ} \mathrm{C}\right.$ in 1.3 $\mathrm{s}$ and hold for $2 \mathrm{~s})$ and heat a strong stimulus $\left(32-48{ }^{\circ} \mathrm{C}\right.$ in $3 \mathrm{~s}$ and hold for 2 s) was used. Each stimulus was repeated twice and the average result used for the analysis. The signal driving the thermal stimuli and the raw electrophysiological data were recorded using a Powerlab 4/30 system and Labchart 7.1 software (AD Instruments) with the spikes-histogram extension.

\section{Analysis of behavior.}

The timings of licks were recorded and used to confirm the detection of a stimulus. If mice licked in a 3-s window of opportunity from the start of the stimulus, the trial was counted a hit.

\section{Analysis of intrinsic optical imaging.}

We analyzed intrinsic optical signal responses to cooling and tactile stimulation of the forepaw using Image $\mathrm{J}$ (Fiji) and custom-written scripts in IgorPro. Image was blurred by Gaussian filter, maxima were determined and the center of the mass. The response area was calculated at $80 \%$ of the peak response amplitude. The response overlap was calculated relative to the area evoked by touch stimuli.

\section{Analysis of whole-cell recordings.}

All recorded neurons were included in the data set if the mean membrane potential was $<-45 \mathrm{mV}$. Sensory responses were averaged and the peak $V_{m}$ value during stimulus presentation was measured. Time to peak was measured as the difference in time between the peak subthreshold response amplitude and the stimulus onset. For tactile stimuli, the evoked subthreshold response amplitude was measured as the peak response amplitude during the stimulus subtracted from a baseline measurement before the stimulus onset. For cooling stimuli, the evoked response amplitude was taken as the average $V_{m}$ in a window $\pm 250 \mathrm{~ms}$ around the peak subthreshold response subtracted from an average baseline $V_{m}$ measurement from a separate 500ms window before stimulus onset. To measure the number of evoked APs, we subtracted the numbers of APs during the entire cooling or tactile stimulus period from an equivalent period of time before stimulus onset. Latency was 
measured as the time point that a sigmoid curve fit of the averaged subthreshold sensory response reached $10 \%$ of its maximal amplitude. around the peak cooling response.

\section{Analysis of extracellular afferent recordings.}

The proportion of cold sensitive fibers was first ascertained in survey experiments where all units were included in the dataset. Later, cold sensitive units were sought out for recordings and further analysis of the threshold. This search technique means that the number of cold-sensitive units analyzed was often larger than the numbers indicated in first survey experiments (for example, Fig. 7b,c and Supplementary Fig. 7). Spike sorting was performed with the spike analysis plug-in of the Chart software (AD instruments). Latency was measured as time to first spike from stimulus onset.

\section{Statistical analysis.}

Statistical analyses were performed with IgorPro and GraphPadPrism 5.0/6.0. No statistical methods were used to predetermine sample sizes, but our sample sizes are similar to those reported in previous publications in the field $^{9,11}$. To test for normality we used a Kolmogorov-Smirnov test. Statistical tests for significance are stated in the text and include one-way ANOVA followed by a Tukey post-hoc comparison, Student's two-tailed paired or unpaired $t$-test, paired Wilcoxon signed rank test or an unpaired WilcoxonMann-Whitney two-sample rank test, $X^{2}$, and Fisher's exact test. Statistical tests between categories in Figure 5 were made between the hit rates after subtraction of the corresponding fail rate. All tests were two-tailed and all data are presented as mean \pm s.e.m. Experiments with Trpm $^{-/-}$and litter-mate control Trpm $8^{+/+}$mice were performed and analyzed blind to genotype, for the rest of the experiments no blinding or randomization was done.

\section{Additional references}

51. Poulet, J. F. A. \& Petersen, C. C. H. Internal brain state regulates membrane potential synchrony in barrel cortex of behaving mice. 
Nature 454, 881-885 (2008).

52. Stürzebecher, A. S. et al. An in vivo tethered toxin approach for the cellautonomous inactivation of voltage-gated sodium channel currents in nociceptors. J. Physiol. (Lond.) 588, 1695-1707 (2010).

53. Milenkovic, N. et al. Nociceptive tuning by stem cell factor/c-Kit signaling. Neuron 56, 893-906 (2007).

54. Koltzenburg, M., Stucky, C. L. \& Lewin, G. R. Receptive properties of mouse sensory neurons innervating hairy skin. J. Neurophysiol. 78, 1841-1850 (1997). 


\section{SUPPLEMENTARY FIGURE LEGENDS}

Supplementary Figure 1: Examples of learning curves and lick timing from individual mice during thermal detection task. a, Examples of individual learning curves from 3 mice, bold cyan line showing the correct hit rate, light cyan the false licks. Mice were trained one session/day. b, Peristimulus time histograms (PSTHs) of licking during stimulus presentation from day 5 from the corresponding mice in a. Thermal stimulus onset is at time = Os and lasted for $3 \mathrm{~s}$. Top PSTHs shows the successful hits, bottom PSTHs in light cyan show the false licks.

\section{Supplementary Figure 2: A cold responsive L2/3 excitatory cortical} pyramidal neuron in mouse forepaw S1. a, Anatomical reconstruction of a cortical pyramidal neuron in mouse forepaw somatosensory cortex. $\mathbf{b}$, Single trial examples of the response of the same cell to cold stimulation of the paw under isoflurane anesthesia with averaged membrane potential response underneath and PSTH on bottom to 40 presentations of a cooling stimulus. Horizontal marks on $\mathrm{V}_{\mathrm{m}}$ represent $-60 \mathrm{mV}$ for single trials and $-74 \mathrm{mV}$ for the averaged response.

Supplementary Figure 3: Mouse forepaw does not move during cooling thermal stimulation under isoflurane anesthesia. a, b, c, Three example, averaged Layer 2/3 cortical whole-cell recordings (black traces) from different mice during cold-thermal $\left(32-22^{\circ} \mathrm{C}\right)$ stimulation of the forepaw (blue trace). the distance of paw movement (orange) was monitored with a movement sensor arm resting on top of the forepaw digits while the force was kept constant (green). The movement sensor was sensitive enough to record a slow (about $3 \mathrm{~s}$ duration) movement of the peltier element during cooling that moved the paw by about $1 \mu \mathrm{m}$. This slight movement did not cause responses in cortex as (i) cortical control recordings showed no response, data not shown; (ii) the same stimulator was used for single nerve afferent fibers recordings and did not evoked tactile responses in low threshold mechanoreceptors; (iii) the cold response starts before movement onset in the middle cell, see vertical red 
dashed line in (b). Horizontal marks next to $\mathrm{V}_{\mathrm{m}}$ represent, (a) $-56 \mathrm{mV}$, (b) -64 $\mathrm{mV},(\mathbf{c})-64 \mathrm{mV}$.

Supplementary Figure 4. Layer $2 / 3$ cortical neurons in $\mathrm{Trpm}^{-/-}$mice respond to tactile stimulation of the forepaw. a, b, c, Three example cells from different mice showing significant averaged subthreshold responses (magenta) to $100 \mathrm{~Hz}$ vibrotactile stimulation (orange) of the forepaw digits.

Supplementary Figure 5. $\operatorname{Trpm}^{-/-}$mice are able to learn an acoustic detection task. a, cartoon schematic of head-restrained mouse undergoing acoustic training with water rewards. $\mathbf{b}, 2 \mathrm{Trpm}^{-/-}$mice were trained to lick in response to brief $(5 \mathrm{~ms}$ ) acoustic stimulus presentation at randomized times directly after cooling detection training. These Trpm $^{-/}$mice were not able to learn to report mild cooling, they learned to lick after the acoustic stimulus already in the first trial. On the fourth session, the mean hit rate was $86.1 \pm$ $3.0 \%$ (mean in purple) compared to false licks $8.5 \pm 3.5 \%$ (mean in black). Error bars show s.e.m.

Supplementary Figure 6. Primary sensory afferent recordings from $\operatorname{Trpm}^{+/+}$and $\mathrm{Trpm}^{-/-}$mice during a $10{ }^{\circ} \mathrm{C}$ cooling stimulus. a, Example recordings from cutaneous C-fibers in WT (blue) and $\operatorname{Trpm}^{-/-}$(magenta) mice during cold stimulation matching the stimulus used during behavioral training $\left(32-22^{\circ} \mathrm{C}\right)$. Inset shows colored spikes that were selected for analysis, and in grey the discarded spikes. b, Temperature threshold for the first spike in all fibers responding to cold. In good agreement with the dataset in Figure 6, very few cold responsive $A-\beta$ or $A-\delta$ fibers were identified with the $10^{\circ} \mathrm{C}$ cooling stimulus. In comparison, a large number of C-MHC (CMechanoHeatCold) and C-MC (C-MechanoCold) fibers with low response threshold were identified. The C-fiber population showed a large reduction in Trpm $^{-/-}$mice. Grey dot shows a unimodal, cold specific C-fiber with similar threshold to other cold sensitive C-fibers. Horizontal bars represent mean with s.e.m..

Supplementary Figure 7. Population analysis of all fibers recorded in entire dataset from $\operatorname{Trpm}^{-/-}$and $\operatorname{Trpm}^{+/+}$mice. a, From the entire surveyed population, $15.6 \%$ (24/154 single units) responded to cooling in 
$\mathrm{Trpm}^{\mathrm{H}}{ }^{++}$mice but only 5.7\% (11/193 single units) in the $\mathrm{Trpm}^{-/-}$mice (Chisquared test $P=0.0024)$. There was no change in the proportion of heating sensitive afferents in the $\mathrm{Trpm}^{-/-}$mouse. b From the four subtypes of $\mathrm{C}$ recorded (C-M, C-Mechano; C-MH, C-MechanoHeat; C-MC, C-MechanoCold, C-MHC, C-MechanoHeatCold), there was a significant reduction in the numbers of recorded C-MC (Chi-squared test $P=0.0025$ ) and no C-MHCs were identified, but there was no change in the numbers of in $\mathrm{C}-\mathrm{M}$ and $\mathrm{C}-\mathrm{MH}$ in the $\operatorname{Trpm}^{-/-}$mouse. C, We recorded 5 major types of A fiber (A- $\beta$; A- $\delta$; A$\beta C ; A-\delta C ; A-\delta H)$ none of which showed significant changes in numbers in the Trpm $^{-/}$mouse. 
a

b

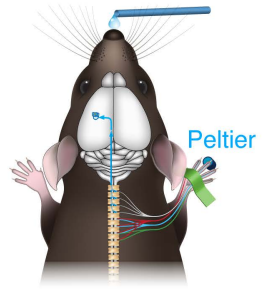

Hit

False

Miss

Rejection

Thermal ${ }^{32^{\circ} \mathrm{C}}-{ }_{-}$
stimulus
$22^{\circ} \mathrm{C}$

Catch

stimulus

Lick

Reward
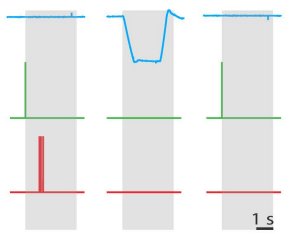

C
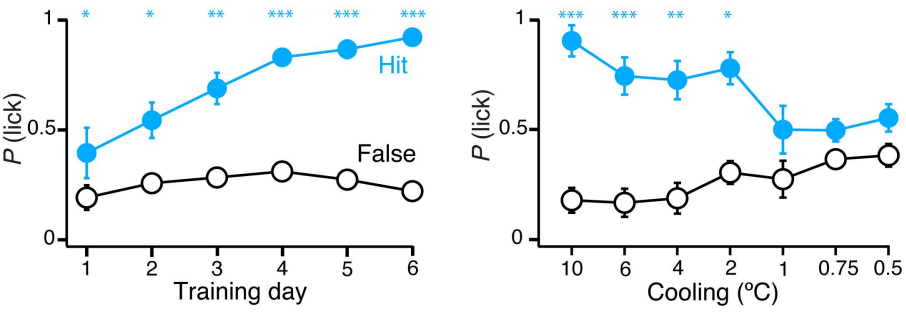

Figure 1

Milenkovic et al 
a

Single trials

$v_{m}(m V)$ | $20 \mathrm{mV}$

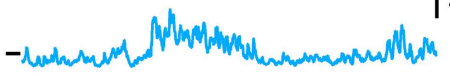

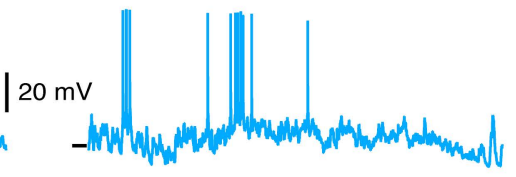

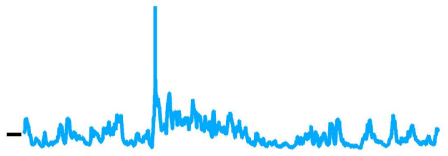

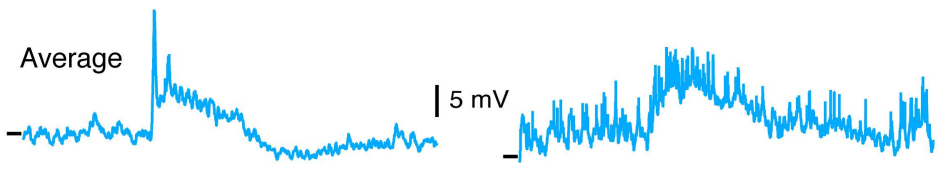

Temperature

$22^{\circ} \mathrm{C}$

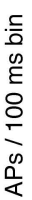

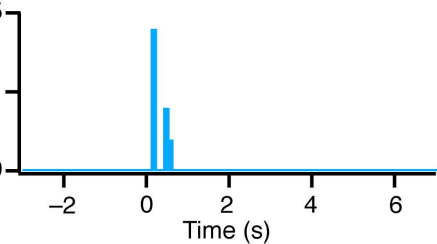

Absolute$$
\begin{array}{r}
1 \\
1 \\
\text { हे } \\
-1 \\
-1
\end{array}
$$$$
\begin{array}{r}
1 \\
1 \\
\\
\text { हे } \\
-1 \\
-1
\end{array}
$$

evoked $V_{m}$

Evoked $V_{m}$

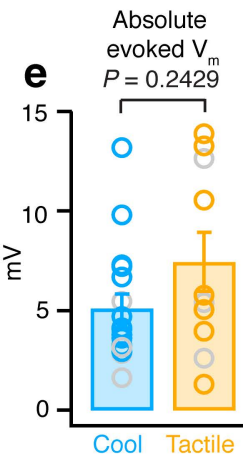

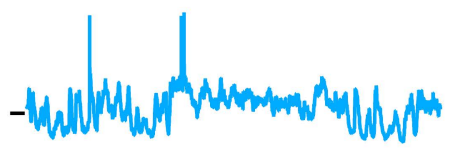

C
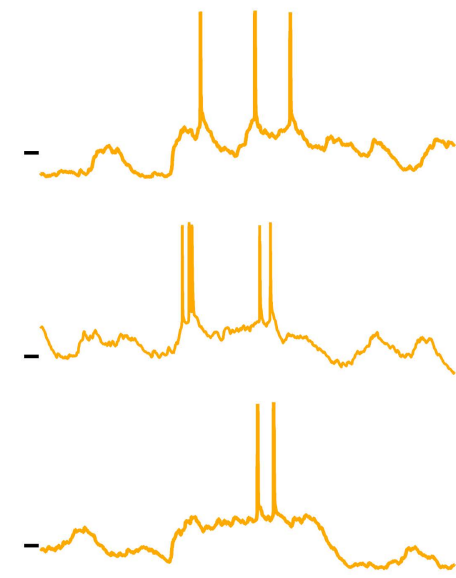

Tactile

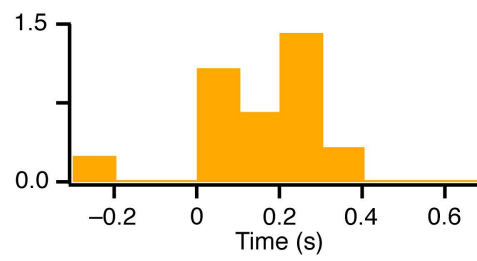

Absolute
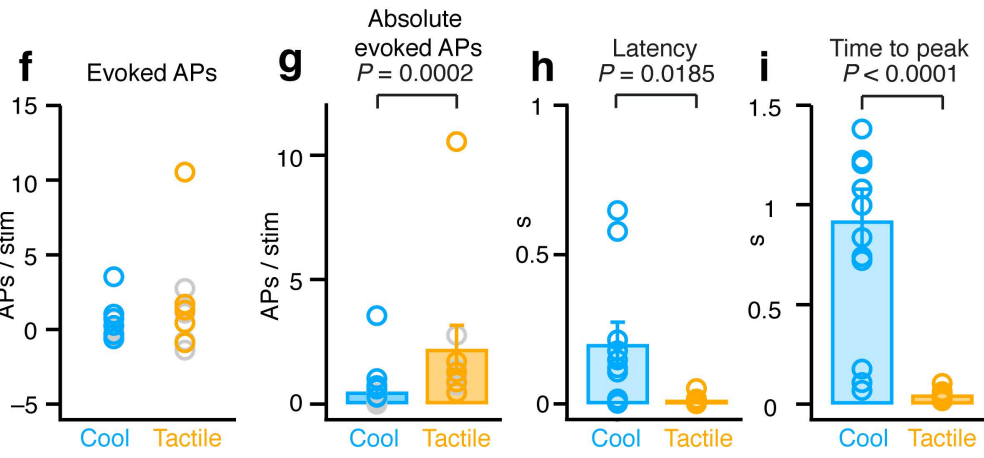

Figure 3

Milenkovic et al 

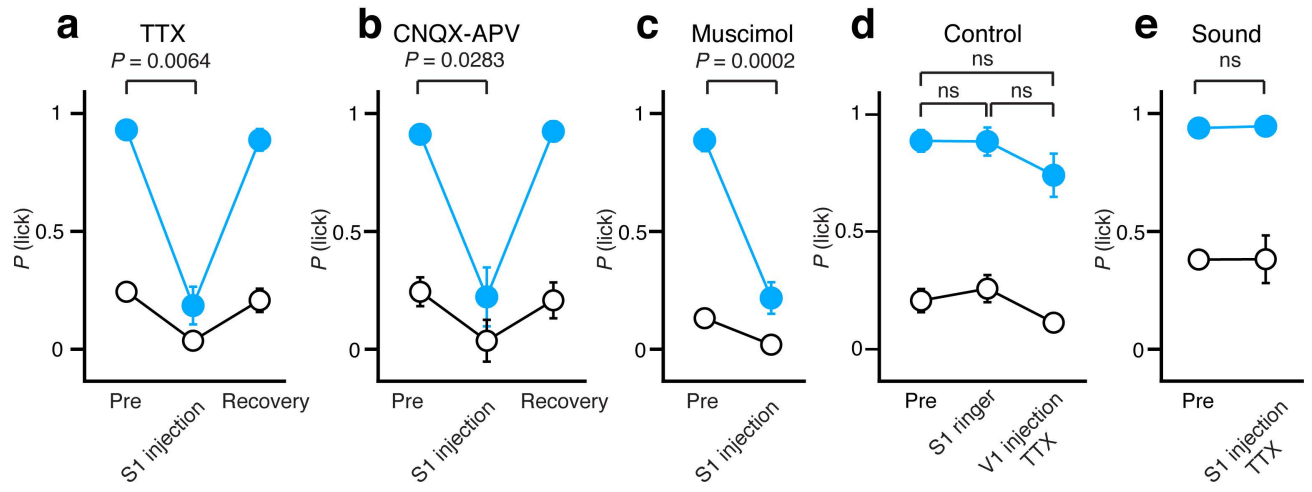

Figure 5

Milenkovic et al 
Single trials
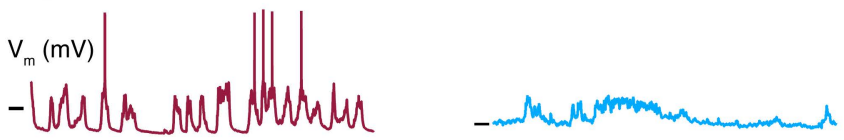

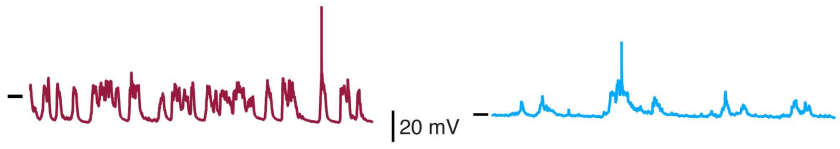

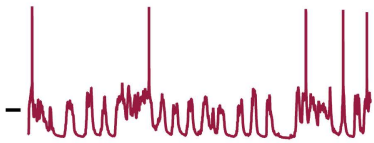

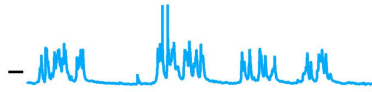

Average

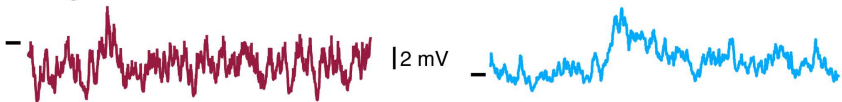

Temperature

$32^{\circ} \mathrm{C}$

$22^{\circ} \mathrm{C}$

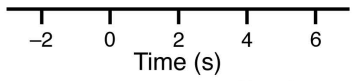

Absolute

C Evoked $V_{m}$ d $\begin{gathered}\text { evoked } V_{m} \\ P=0.0333\end{gathered}$

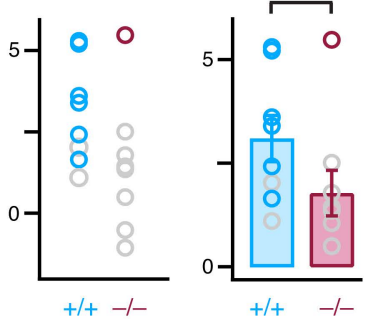

$32^{\circ} \mathrm{C}$ $22^{\circ} \mathrm{C}$

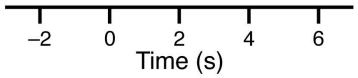

e

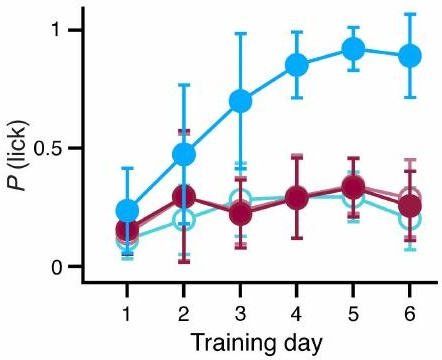

Figure 6

Milenkovic et al 
a ${ }_{T R P M} 8^{+/+}$

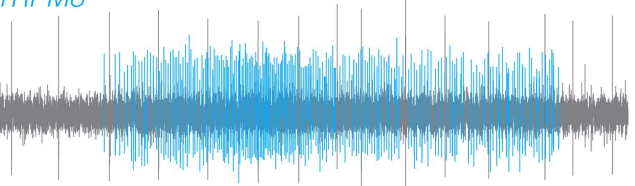

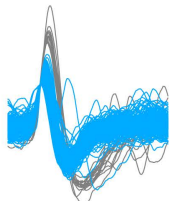

TRPM $^{-/-}$

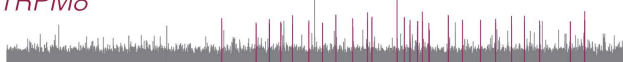

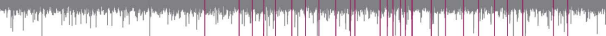

Temperature

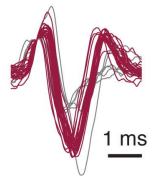
$32^{\circ} \mathrm{C}-$
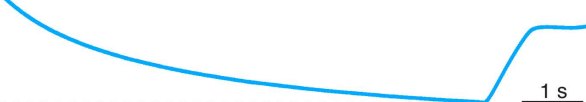

b

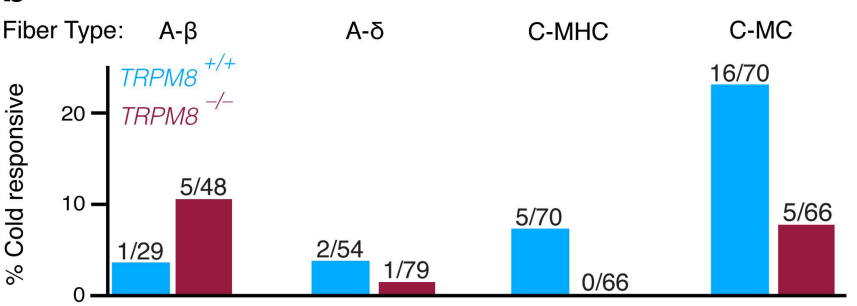

C

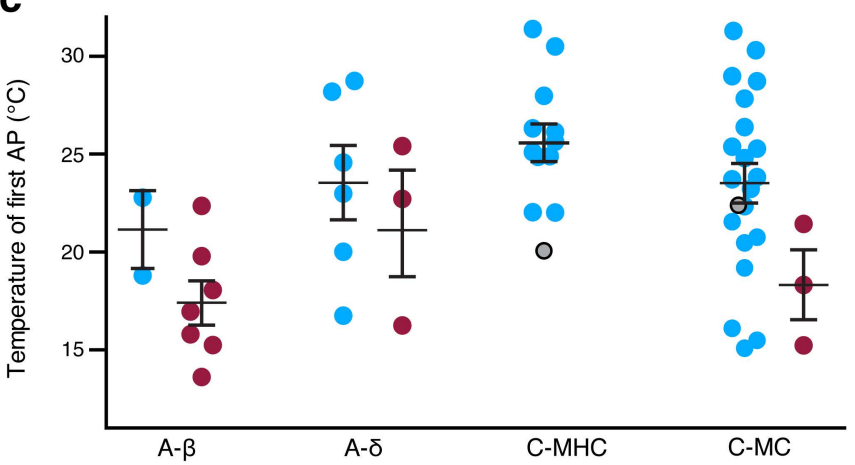

d

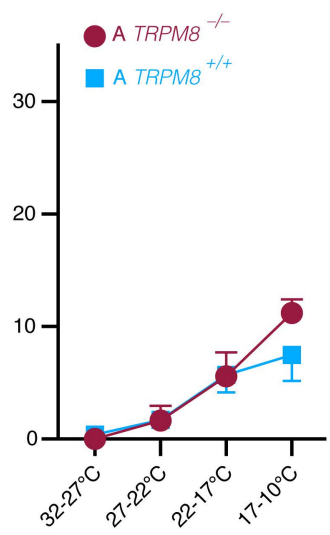

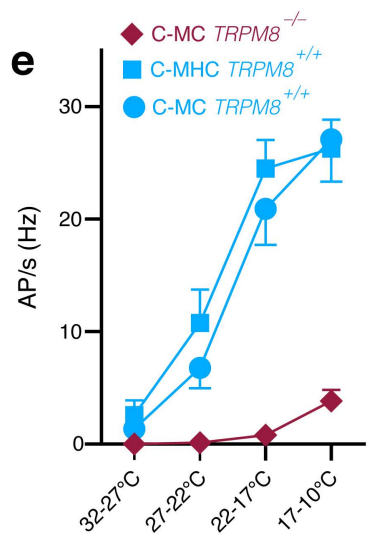

Figure 7

Milenkovic et al 
a Learning curves

\section{Mouse 1}

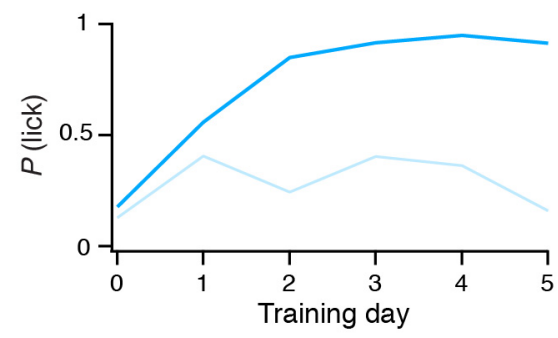

b Licking PSTHs
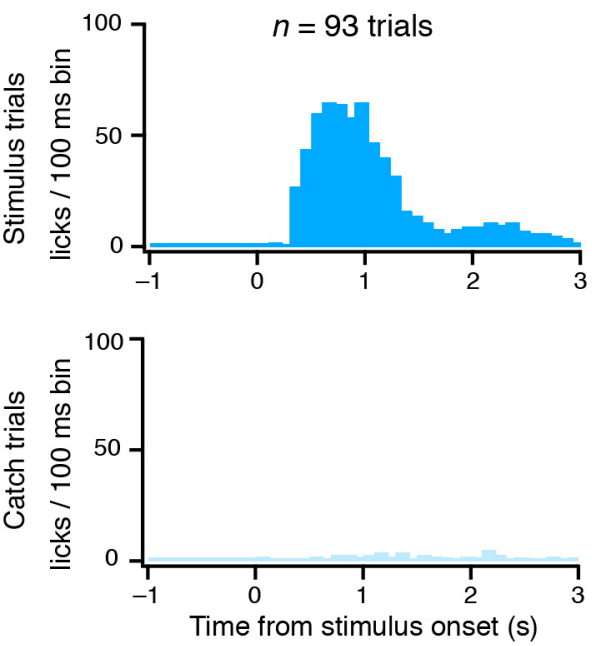

Mouse 2
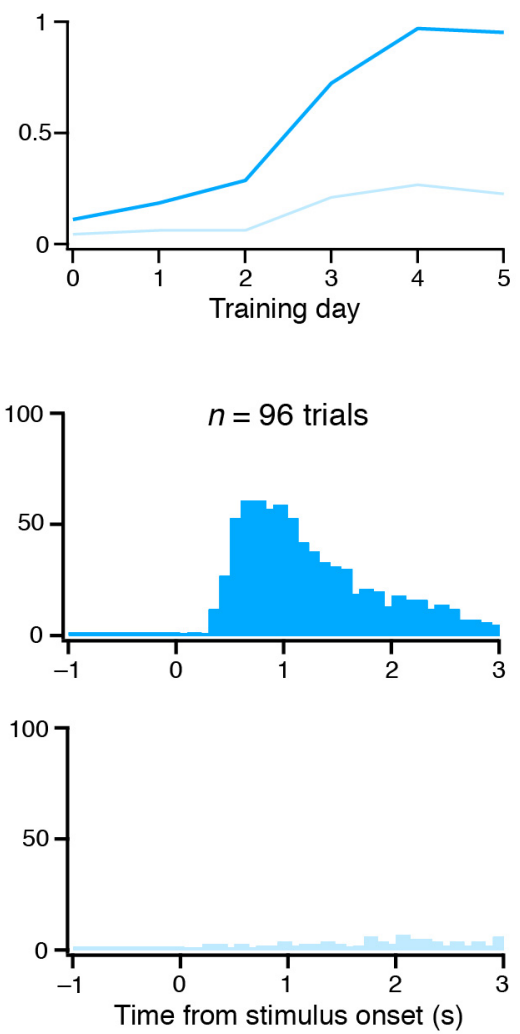

Mouse 3
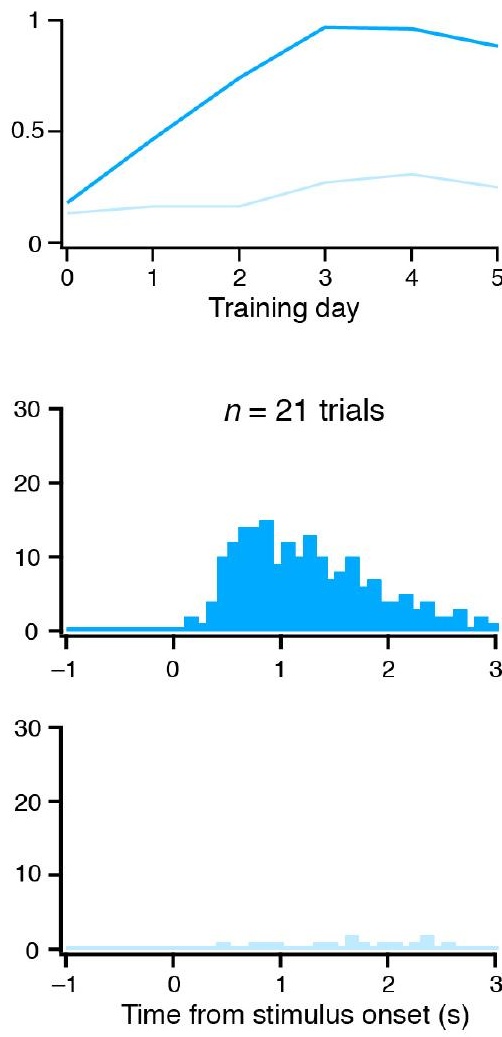
$\mathbf{a}$

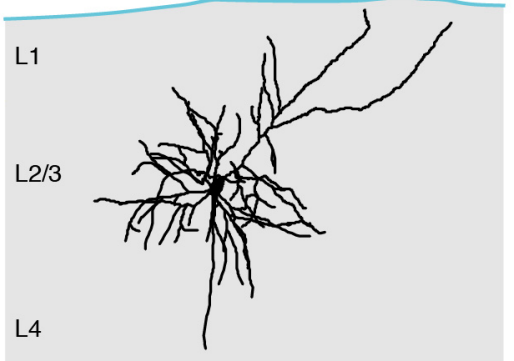
L5
$200 \mu \mathrm{m}$

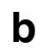

singletrals

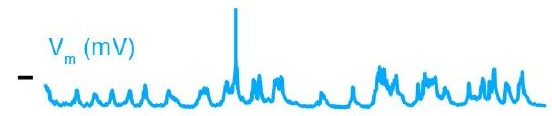

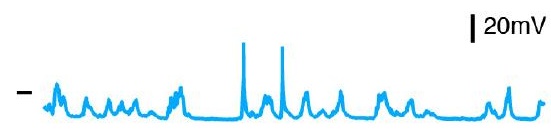

Average $\quad 4 \mathrm{mv}$

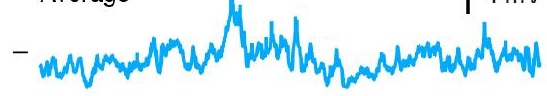

Temperature

2

$22^{\circ} \mathrm{C}$

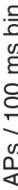

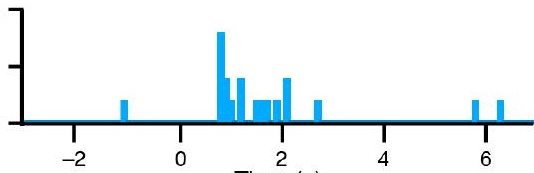

Time (s) 


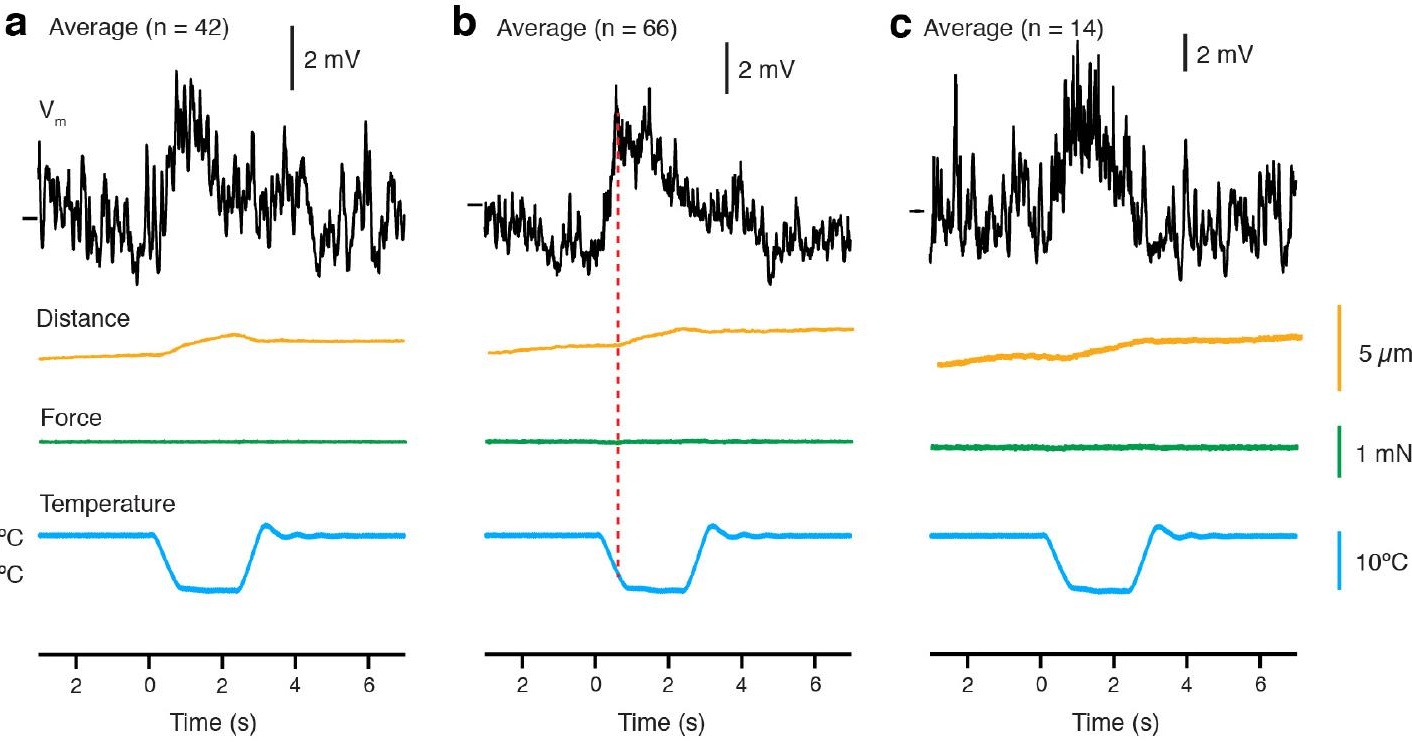




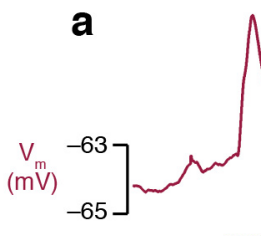

A $\quad P<0.0001 \quad$ b

Tactile stimulus

$\overline{200 \mathrm{~ms}}$

$-62$

$P<0.0001$

C

$n=84$

$n=72$

$\underbrace{\left.\begin{array}{rr}n=72 & -61 \\ & \end{array}\right]}_{n}$

$P<0.0001$
$\mathrm{n}=42$

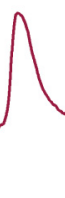

$\overline{200 \mathrm{~ms}}$

$200 \mathrm{~ms}$ 


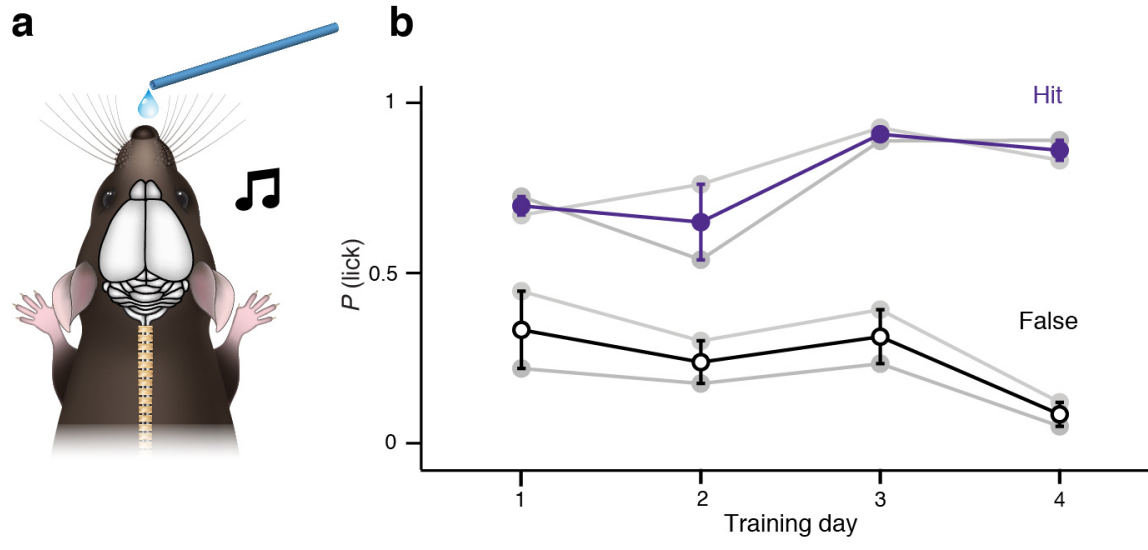


a

TRPM8 $8^{+/+}$

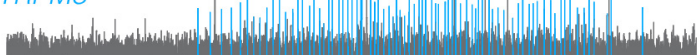

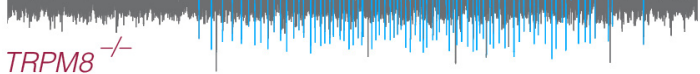

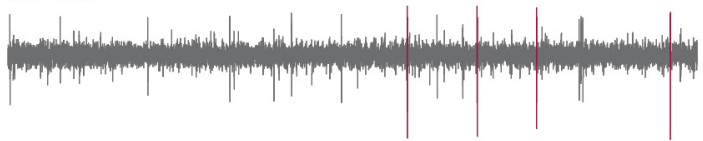

Temperature $22^{\circ} \mathrm{C}$

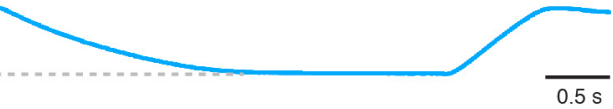

b
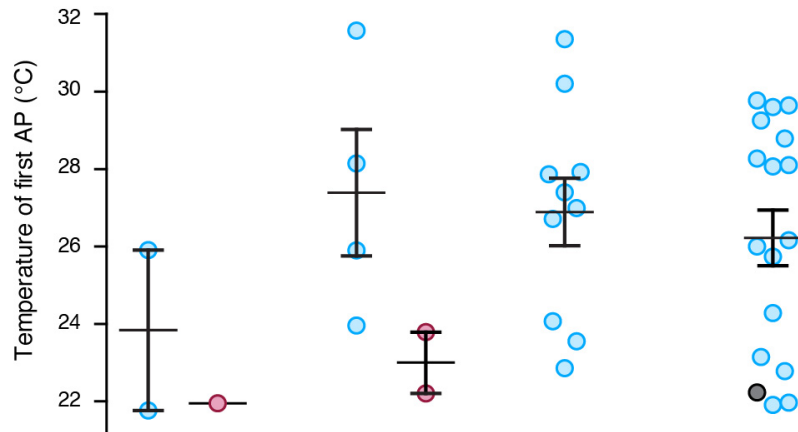

$1 \mathrm{~ms}$
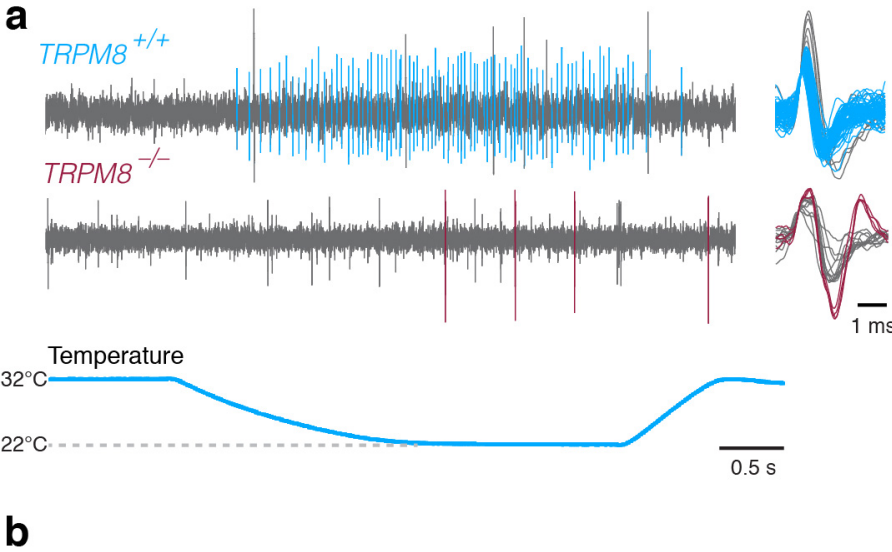

O

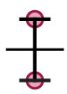

C-MHC

C-MC
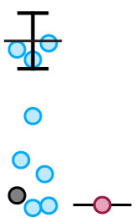

A-ठ

FiberType: $\quad$ A- $\beta$ 


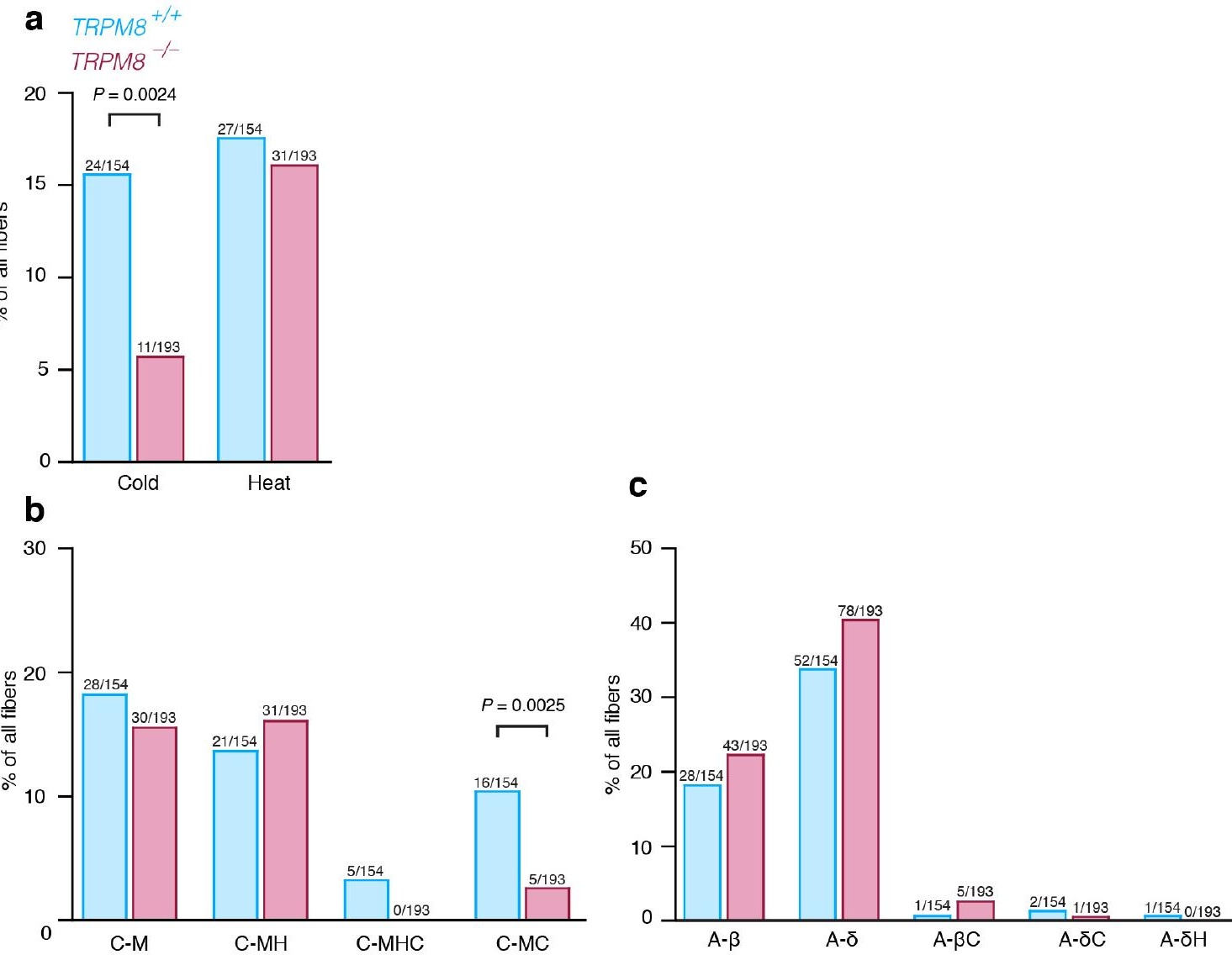

